\title{
PERIPHERAL NEURAL MECHANISMS OF CUTANEOUS HYPERALGESIA FOLLOWING MILD INJURY BY HEAT ${ }^{1}$
}

\author{
ROBERT H. LAMOTTE, ${ }^{2}$ JOHANN G. THALHAMMER, ${ }^{3}$ H. ERIK TOREBJÖRK, ${ }^{4}$ AND \\ CHARLES J. ROBINSON ${ }^{5}$
}

Department of Anesthesiology, Yale University School of Medicine, New Haven, Connecticut 06510

Received October 19, 1981; Revised January 25, 1982; Accepted January 25, 1982

\begin{abstract}
Pain thresholds in humans were determined for heat stimulations of the skin before and after a mild injury induced by a single conditioning stimulus (CS) of $50^{\circ} \mathrm{C}$ and $100 \mathrm{sec}$ duration. The same stimuli were delivered to the receptive fields of $\mathrm{C}$ fiber and $\mathrm{A}$ fiber mechanoheat-sensitive nociceptors (CMH and AMH nociceptors, respectively) and of low threshold warm and cold receptors in the anesthetized monkey and to the receptive fields of $\mathrm{CMH}$ nociceptors recorded percutaneously from the peroneal nerve of awake humans. Pain thresholds in normal skin were matched only by the response thresholds of $\mathrm{CMH}$ and not $\mathrm{AMH}$ nociceptors. Immediately following heat injury, some pain thresholds and CMH response thresholds were elevated, but by 5 to $10 \mathrm{~min}$ after the CS, pain and $\mathrm{CMH}$ thresholds were lowered to 2 to $6^{\circ} \mathrm{C}$ below normal (hyperalgesia and nociceptor sensitization). No other type of cutaneous receptor studied exhibited changes in threshold similar to those observed for pain and for CMH nociceptors. The magnitude of hyperalgesia in humans and the magnitude of sensitization of CMH nociceptors in monkeys following heat injury were greater for hairy than for glabrous skin. The time course of the development of hyperalgesia was not altered by ischemia or conduction block in A fibers. The results support the conclusion that altered activity in $\mathrm{CMH}$ nociceptors is a major peripheral determinant of cutaneous hyperalgesia following a mild heat injury to the skin.
\end{abstract}

Following a mild cutaneous injury, there is often a sensation of burning pain and enhanced pain sensitivity of the skin. The threshold or minimal intensity of cutaneous stimulation required to evoke a pain sensation is lowered so that even normally innocuous stimuli may be perceived as mildly painful. Further, there is an enhanced painfulness of stimuli that are normally painful and, in some instances, spontaneous pain without externally ap-

' This work was supported by Public Health Service Grant NS 14624. E. T. was supported in part by the above and by Swedish Medical Research Council Grants B82-14X-02506-05 and B82-14P-615301A. We wish to thank Dr. David Stagg and Mr. Philip Marks for their aid in computer programming and Dr. Gerald Beck for his advice during the statistical analyses.

${ }^{2}$ To whom correspondence should be addressed at Department of Anesthesiology, Yale University School of Medicine, 333 Cedar Street, New Haven, CT 06510.

${ }^{3}$ Present address: II. Physiologisches Institut, University of Heidelberg, Im Neuenheimer Feld 326, 6900 Heidelberg, West Germany GFR.

${ }^{4}$ Present address: Department of Clinical Neurophysiology, University Hospital, S-75014, Uppsala, Sweden.

"Present address: Rehabilitation Engineering Research and Development Center, Hines Veterans Administration Hospital, Box 20, Hines, IL 60141 . plied stimulation. One or more of these altered pain sensations are descriptive of the state of cutaneous hyperalgesia (Lewis and Hess, 1933; Hardy et al., 1952; Lynn, 1977). Cutaneous hyperalgesia may result not only from direct injury to the skin but from a variety of pathologies involving the peripheral or central nervous system (Hardy et al., 1952).

Hyperalgesia resulting from a well defined stimulus, such as heat applied to the skin, might be expected to have a basis more amenable to study and thus might serve as an experimental model of clinical cutaneous hyperalgesia. In the present study, we searched for the peripheral neuronal determinants of heat-pain thresholds and of alterations in pain thresholds following mild injury by heat.

Neurophysiological studies of single cutaneous afferents have described several types whose receptor endings are sensitive to heat and thus may contribute to altered changes in cutaneous sensation following injury by heat. High threshold receptors or "nociceptors" have either A fibers (A nociceptors) or C fibers (C nociceptors) (Zotterman, 1936, 1939). Nociceptors of either of these generic fibcr types differ in their sensitivities to various forms of noxious energies. Some are selectively responsive only to 
noxious mechanical stimuli but not to hot or cold noxious stimuli (Iggo, 1960; Burgess and Perl, 1967; Bessou and Perl, 1969; Beck et al., 1974; Georgopoulos, 1976; LaMotte and Campbell, 1978), while others respond readily to mechanical or thermal stimuli but differ in their sensitivities to noxious chemicals (Adriaensen et al., 1981). Still others are less selective and respond to either mechanical, hot, cold, or chemical stimuli and thus have been termed polymodal nociceptors (Iggo, 1959; Iriuchijima and Zotterman, 1960; Bessou and Perl, 1969; Van Hees and Gybels, 1972; Torebjörk and Hallin, 1974; Adriaensen et al., 1981). In the present study, only mechanical and heat stimuli were used. Thus, A nociceptors and $\mathrm{C}$ nociceptors that were sensitive to mechanical and heat stimuli will be labeled as AMHs and CMHs, respectively. This terminology is not intended to exclude the possibility that these nociceptors also respond to chemical stimuli. Indeed, the latter might account for changes in their sensitivities following heat injury.

Previous studies have shown that certain cutaneous receptors, particularly $\mathrm{CMH}$ and $\mathrm{AMH}$ nociceptors, are capable of being sensitized to heat following injury by heat. Sensitization is characterized by one or more of the following: a lowering of the heat threshold, an cnhanced response to stimuli normally above threshold, and the development of spontaneous discharge without externally applied stimulation (Bessou and Perl, 1969; Beitel and Dubner, 1967a, b; Perl et al., 1976; Fitzgerald and Lynn, 1977; Torebjörk and Hallin, 1977; Campbell et al., 1979). In addition to nociceptors, certain low threshold receptors also may exhibit a change in responsiveness to heat following heat injury. For example, many cold receptors exhibit a paradoxical response to noxious heat (Dodt and Zotterman, 1952; Dubner et al., 1975; Kenshalo and Duclaux, 1977; Long, 1977). It has been shown that this response can be sensitized during or following sufficiently intense heating and therefore might contribute to altered sensory states in hyperalgesic skin (Dubner et al., 1975; Long, 1977).

The understanding of the peripheral neural determinants of hyperalgesia following heat injury to the skin has been clouded by a general disagreement as to the physical and physiological conditions responsible for nociceptor sensitization and by the finding that nociceptors may exhibit an opposite response property-that of "fatigue" or "suppression." The latter is manifested by a decreased response to repetitively delivered mechanical or thermal stimuli (e.g., Perl, 1968; Torebjök and Hallin, 1974; Beitel and Dubner, 1976a; Price et al., 1977; LaMotte and Campbell, 1978). In some studies, sensitization was a predominant characteristic of the nociceptor's response to noxious heat (Beitel and Dubner, 1976a, b; Fitzgerald and Lynn, 1977; Campbell et al., 1979), while in others, suppression and not sensitization (LaMotte and Campbell, 1978; Gybels et al., 1979) or both phenomena (Bessou and Perl, 1969; Croze et al., 1976; Georgopoulos, 1976) were observed. However, these same studies often differed as to the species tested, the type of skin stimulated, the type of nociceptor studied, the patterns and intensities of stimuli delivered, and the extent of injury to the skin brought about by these stimuli. Any or all of these factors may be related to the susceptibility of a nociceptor to changes in the response threshold following heat injury to the skin.

The complexities of the factors that may influence the peripheral neuronal response to heat and the relative paucity of psychophysical studies of hyperalgesia have made it difficult to relate altered pain thresholds following a heat injury of the skin to changes in the response properties of cutaneous receptors. Thus, the purpose of the present study was 4-fold: (1) to determine psychophysically the time course of changes in the pain threshold to heat following a mild injury produced by a heat stimulus maintained at constant temperature and of sufficient duration to render the skin hyperalgesic; $(2)$ to deliver a sequence of heat stimuli, identical to that used in the psychophysical experiments, to the receptive fields of CMH and AMH nociceptors and low threshold warm and cold receptors in the monkey in order to determine whether alterations in the sensitivities of these receptors might contribute to the observed threshold changes in human pain sensation; (3) to determine how measures of the pain threshold and thresholds of nociceptors vary with differences in the type and location of skin tested and other parameters that might influence the results obtained; and (4) to replicate a portion of these studies during percutaneous recordings from $\mathrm{CMH}$ nociceptive afferents in the peripheral nerve of the awake human.

\section{Materials and Methods}

\section{Psychophysical Methods}

Naive human subjects participated in the experiments after giving informed consent to a protocol previously approved by the University's Human Investigation Committee. The subjects made continuous ratings of the magnitude of pain sensation during experiments in which heat stimuli were applied to the skin. The subject indicated the magnitude of pain by moving a lever along a scale (20-cm line) marked off in divisions of $4 \mathrm{~cm}$, intended to represent a continuum of subjective intensity. Five Greek letters were spaced evenly over the scale. The subject was told that the markings on the scale were not intended to represent equal divisions of sensory intensity but were there only to facilitate memory of previous ratings of pain. Each subject was told to rate only the sensory magnitude of pain and not his reaction to pain, such as how tolerable or unpleasant the sensation may be. If there were no pain, e.g., only warmth, the subject was to indicate the absence of pain by keeping the lever at the bottom mark on the scale. Each was to rate pain continuously, indicating when the pain began and its time course of increase and decrease. No information was given as to the number, durations, or sequence of stimuli. During a training session, when data were not collected, seven heat stimuli were delivered to the subject's volar forearm in ascending order of temperature in steps of $2^{\circ} \mathrm{C}$ from 39 to $51^{\circ} \mathrm{C}$. The stimuli, each of $5 \mathrm{sec}$ duration, were delivered every $30 \mathrm{sec}$ on a base temperature of $38^{\circ} \mathrm{C}$. After the stimulus of $49^{\circ} \mathrm{C}$, there was a brief pause, and the subject was told that the next stimulus $\left(51^{\circ} \mathrm{C}\right)$ would be slightly more intense than the last and that he should rate the magnitude of pain sensation such that the lever was brought to within the top third of the scale 
when the pain sensation reached a maximal level. His memory of this maximal level was to serve as a standard for all subsequent ratings. Following this, the hyperalgesia experiments as described below were begun.

\section{Experimental Control, Data Collection, and Data Analyses}

A voltage analog of the subject's ratings was obtained via a potentiometer attached to the subject's response lever. This signal and a voltage representation of stimulus temperature were displayed in real time on a high resolution video display (VT11) and stored on a disc via a PDP 11/34 computer. Off-line data analyses provided such information as the maximal rating of pain for each stimulus, latency of pain, pain duration, the area under the time-intensity rating curve, and other data as will be described in a subsequent paper.

The computer also controlled the timing and intensities of the thermal stimuli which were delivered via a round silver plate (thermode) of $1.2 \mathrm{~cm}$ diameter pressed gently against the skin. Stimulus temperature was measured at the interface between the thermode and the skin via a thermocouple glued to the bottom of the silver plate. Stimulus temperature was maintained at the desired level to within $\pm 0.1^{\circ} \mathrm{C}$ by a local analog control circuit. The rise time to two-thirds of the desired increment above the control base temperature was $260 \mathrm{msec}$. Further details on the thermode are available elsewhere (Darian-Smith et al., 1973).

\section{Electrophysiological Recordings in Anesthetized Monkeys}

Recordings were made of action potentials in single, afferent, peripheral nerve fibers of Macaca fascicularis monkeys. The monkeys were anesthetized with intravenous administration of sodium pentobarbital. Five percent dextrose was administered intravenously throughout the experiment. Core temperature was monitored via a rectal probe and maintained at $37 \pm 1^{\circ} \mathrm{C}$ with the use of a heating pad. Action potentials were recorded by means of conventional microdissection and electrophysiological techniques (e.g., La Motte and Campbell, 1978) from primary afferent nerve fibers in the median and ulnar nerves, the superficial radial nerve innervating the wrist and hand, and the saphenous nerve innervating the ankle and foot. The action potentials were converted to digital events, displayed in real time on the video display along with the signal representing the stimulus temperature, and stored on a disc by the computer. During the search procedure, neuronal activity in single warm or cold fibers was identified by briefly warming the skin $\left(<40^{\circ} \mathrm{C}\right)$ by means of a heat lamp. Activity in mechanosensitive nociceptive afferents was identified from pressure applied to a local region of the skin with the experimenter's fingers (pinching or kneading the skin). Such stimuli were faintly painful when applied to the skin of human observers. Upon isolating activity in a single nociceptive afferent fiber, its receptive field was mapped with nylon monofilaments of the von Frey type. The thermode then was centered over the receptive field, and a series of heat stimuli, as described below, were delivered starting about 5 min after the last mechanical stimula- tion. At the end of the experiment, conduction velocity was determined by electrical stimulation through needles inserted into the skin near or within the receptive field.

Great care was taken to insure that the receptive field of each receptor to be studied was located within an area of skin that had received no previous noxious heat stimulations (or such noxious mechanical stimuli as insertion of a needle into the skin) nor was within $1 \mathrm{~cm}$ of an area that had received such stimulation. Consequently, at best, only a small number of receptors could be studied in each nerve experiment.

\section{Percutaneous Electrophysiological Recordings in the Awake Human}

Recordings were obtained at knee level from the peroneal nerve innervating the lateral calf and the dorsum of the foot from a population of 14 human subjects. The subject was seated comfortably in a reclined position in a dental chair with his foot held securely in Plasticine. The nerve was located by palpation and by electrical stimulation through the recording electrode. The electrode was inserted manually through the skin and into the nerve. Action potentials from single CMH nociceptive afferents were recorded on FM tape for subsequent off-line analysis. Only unitary activity that could be safely discriminated from background discharges in other afferents or in sympathetic efferents was included in our analyses. Further details concerning the recording techniques are available elsewhere (Torebjörk and Hallin, 1974). A search for unitary activity was carried out either by gently scraping the skin with a sharp piece of plastic or by electrical microstimulation through the tip of the electrode. During the latter, the subject would control the current of a continuous train of square wave pulses, each of 0.25 msec duration delivered at a frequency of 3 $\mathrm{Hz}$. The subject would report the quality of sensation that he felt as well as the locus on the skin to which the sensation was referred. The latter served to direct the experimenter's attention to the appropriate location on the skin so that mechanical stimulation could be applied there. Upon isolating activity in a single, unmyelinated, nociceptive afferent, the receptive field was mapped by applying monofilaments capable of delivering different forces to the skin. Next, the thermode was centered over the receptive field and the standard series of heat stimuli was delivered (see below). During each recording, the subject made continuous ratings of pain during heat stimulation. No auditory or visual signals concerning the stimuli or nerve impulse activity were available to the subject during his performance. At the end of the experiment, conduction velocity was determined by electrical stimulation through electrodes inserted into the skin within the receptive field.

\section{Experimental Design}

\section{Determinations of pain threshold in humans and response thresholds of CMH nociceptors in monkeys and humans}

Single test stimulus. In a preliminary psychophysical experiment, 4 subjects were given a single test stimulus to the volar forearm either before or at $0.5,1.0,1.5,3.0$, 
or 5.0 min after a conditioning stimulus $(\mathrm{CS})$ of $50^{\circ} \mathrm{C}$ and $100 \mathrm{sec}$ duration delivered to the same locus on the skin. The temperature of the test stimulus was varied randomly from one day to the next over a range of 39 to $51^{\circ} \mathrm{C}$ in steps of $2^{\circ} \mathrm{C}$. The stimulus duration was $5 \mathrm{sec}$ and each stimulus was delivered on a base temperature of $38^{\circ} \mathrm{C}$. Each stimulus temperature was presented on only one occasion. The pain threshold in this and all subsequent experiments was defined as the minimal temperature eliciting a rating of pain. One determination of the pain threshold was made at each point in time for each subject. The thresholds obtained from each subject were averaged.

Multiple test stimuli. In all psychophysical experiments other than the above and in all neurophysiological experiments, multiple test stimuli were delivered, in the sequence illustrated in Figure 4, to various regions of the glabrous and hairy skin. In this standard test series, heat stimuli of 39 to $51^{\circ} \mathrm{C}$, each of $5 \mathrm{sec}$ duration, were delivered at interstimulus intervals of $25 \mathrm{sec}$ in ascending order of temperature in steps of $2^{\circ} \mathrm{C}$ on a base temperature of $38^{\circ} \mathrm{C}$ before and after a conditioning stimulus (CS) that was typically of $50^{\circ} \mathrm{C}$ and of either 60 or 100 sec duration. An ascending series of 39 to $47^{\circ} \mathrm{C}$ was started at $0.5 \mathrm{~min}$ and again at $5 \mathrm{~min}$ after the CS. The full series of 39 to $51^{\circ} \mathrm{C}$ was delivered starting 10 and 20 min after the CS. A duration of $100 \mathrm{sec}$ for a stimulus of $50^{\circ} \mathrm{C}$ is two-thirds of the shortest duration found to produce irreversible damage to the epidermis (Moritz and Henriques, 1947). The CS and test stimuli resulted in no visible edema, only erythema which lasted for several days. In two recordings from human nerve, a CS of $48^{\circ} \mathrm{C}$ and $5.3 \mathrm{~min}$ duration was substituted for the CS of $50^{\circ} \mathrm{C}$. During the $\mathrm{CS}$ of $48^{\circ} \mathrm{C}$, small incremental pulses of heat, ranging from 0.1 to $1.3^{\circ} \mathrm{C}$, were superimposed now and then on the $48^{\circ} \mathrm{C}$ base temperature in order to determine the sensitivity of CMHs to such stimuli (Robinson et al., 1980).

The response threshold of a cutaneous receptor was the minimal temperature in each ascending temperature sequence that elicited a response of one or more impulses or, in the case of warm fibers, a noticeable increase above background discharge. The pain threshold was the minimal stimulus temperature rated as painful. Thresholds for normal skin were those obtained prior to the CS during the first ascending series of 39 to $51{ }^{\circ} \mathrm{C}$.

\section{The study of possible factors influencing the development of hyperalgesia}

The standard test series was delivered in studies of the effects of alterations in blood flow (ischemia), A fiber block, or small differences in the duration of the CS on the time course of hyperalgesia following the CS.

Ischemia. A pressure cuff was applied to the upper arm of 3 subjects and inflated to and held at $200 \mathrm{~mm} \mathrm{Hg}$ during heat stimulations of the volar forearm over a period beginning just prior to the first test stimulus and extending to the end of the ascending series delivered 10 min after the CS.

Compression block of conduction in $A$ fibers. In 8 subjects, the forearm was held comfortably in Plasticine while the hand lightly gripped a vertical rod held fixed and perpendicular to the axis of the arm. A 2-cm-wide linen band was applied over the superficial branch of the radial nerve at wrist level and the nerve was compressed against the bone by two 2.3-kg weights, one hanging from each end of the band. In addition, supporting clay under pressure from the band also compressed the median and ulnar nerves. A total compression time of 40 to $48 \mathrm{~min}$ was required to eliminate the sense of touch and cold in skin supplied by the radial nerve and, in most cases, areas of skin supplied by the median and ulnar nerves as well. At this time, the thermode was placed quickly on the skin overlying the first interosseous space on the dorsum of the hand (innervated by the radial nerve). The ascending temperature series then was given. Testing was discontinued and the compression block was removed at the end of the ascending series delivered 10 min after the CS. Recovery of sensation proceeded rapidly in all subjects without untoward effects.

Duration of the CS. Four subjects were each tested on the forearm with a $\mathrm{CS}$ of $50^{\circ} \mathrm{C}$, the duration of which was $60 \mathrm{sec}$ in one test and $100 \mathrm{sec}$ in a second test. In neurophysiological studies of hairy skin in the monkey, a CS of $50^{\circ} \mathrm{C}$ was of $100 \mathrm{sec}$ duration for $13 \mathrm{CMH}$ nociceptors tested and $60 \mathrm{sec}$ for 7 other CMHs.

\section{Results}

\section{Comparison of the pain thresholds of humans with} the response thresholds of nociceptors in normal (uninjured) skin in the monkey

Magnitude ratings of pain were obtained from 19 naive subjects during a series of heat stimuli delivered in order of ascending temperature to the forearm. The ratings of one subject are shown in Figure 1 (left). The same sequence of stimuli was delivered to the cutaneous receptive fields of $58 \mathrm{CMH}$ and $45 \mathrm{AMH}$ nociceptors in the monkey. The responses of a CMH and an AMH nociceptor to heat also are illustrated in Figure 1. The response threshold of a nociceptor was not difficult to determine since no nociceptor was spontaneously active in normal skin. Data obtained from the psychophysical and neuronal responses to suprathreshold stimuli in these experiments will be described in subsequent papers.

The distributions of pain thresholds for humans are shown in Figure 2A. Thirteen subjects were tested on the volar forearm while 6 others were tested on the leg or dorsum of the foot. In addition, 8 of the 19 subjects tested on hairy skin were tested subsequently on the thenar eminence of the glabrous skin of the hand. Six of these 8 later were tested on the finger tip and 4 of the latter were tested further on the hypothenar eminence. Paired $t$ tests were used to lest the significance of differences between pain thresholds on hairy skin of the volar forearm and those on each region of glabrous skin (with $\alpha$ levels adjusted by the Bonferroni procedure to allow multiple comparisons) (Harris, 1975). The only significant difference was a $2^{\circ} \mathrm{C}$ lesser mean threshold for the thenar eminence than the obtained for the volar forearm $(p<$ 0.008 ). Repeated measures analyses of variance of the thresholds obtained before and after the CS revealed no differences between values for the arm and the leg or foot. These analyses were obtained (1) for different sub- 


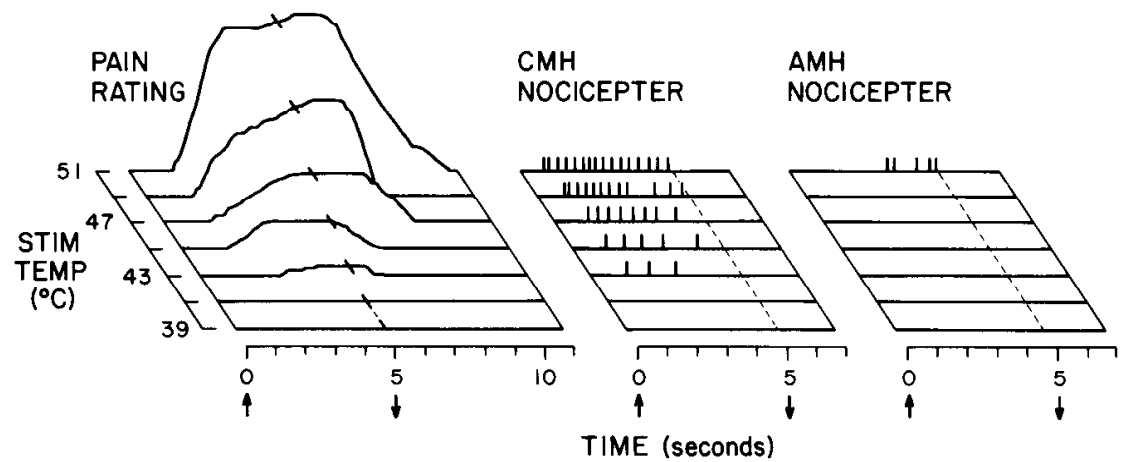

Figure 1. Magnitude ratings of pain by a human subject and evoked activity in a $\mathrm{CMH}$ and $\mathrm{AMH}$ nociceptor in the monkey during heat stimulations of normal skin. Left panel, Magnitude ratings of pain made by a subject during the first heat stimulations of 39 to $51^{\circ} \mathrm{C}$ delivered in steps of $2^{\circ} \mathrm{C}$ to the volar forearm prior to heat injury. Each horizontal line represents the passage of time during one trial. The base temperature was $38^{\circ} \mathrm{C}$. The upward arrow at 0 sec under the abscissa indicates the onset of each stimulus, while the downward arrow and dashed line in the horizontal plane indicate stimulus termination. The vertical axis, which is not shown, represents the magnitude of pain as rated continuously throughout testing. The pain threshold, in this case, was $43^{\circ} \mathrm{C}$, the minimal stimulus temperature that elicited a rating of pain. Middle panel, Responses of a $\mathrm{C}$ fiber mechanoheat nociceptor $(\mathrm{CMH})$ to the same heat stimuli delivered to hairy skin of the anesthetized monkey. Each vertical mark represents a single nerve impulse. The response threshold, in this case, was $43^{\circ} \mathrm{C}$, the minimal stimulus temperature that evoked a response. Right panel, Responses of an A fiber mechanoheat nociceptor (AMH) to the same stimuli delivered to monkey hairy skin. The response threshold was $51^{\circ} \mathrm{C}$.

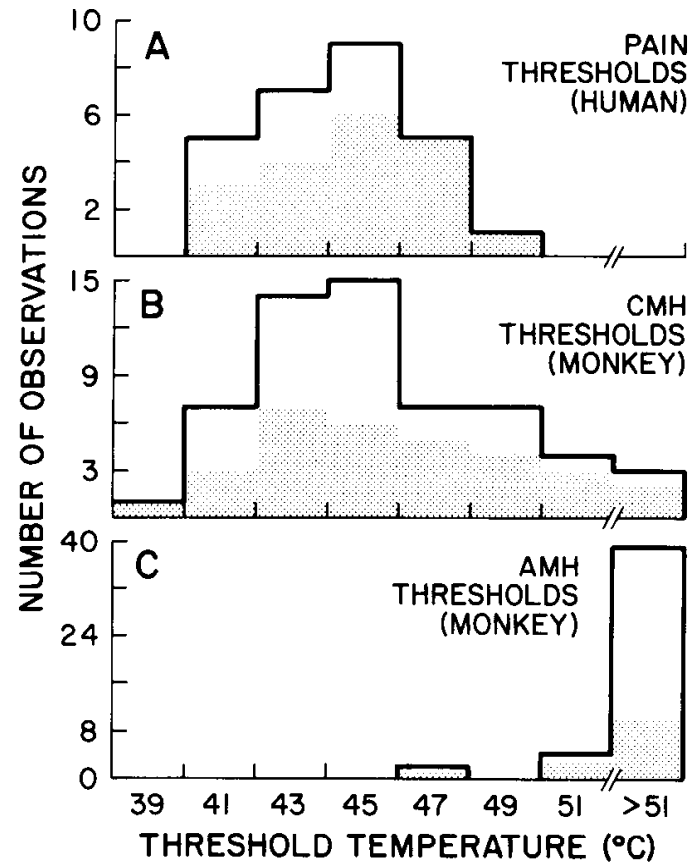

Figure 2. Distributions for normal skin of pain thresholds to heat in humans and response thresholds to heat of CMH and AMH nociceptors in the monkey. The stippled areas represent the number of thresholds of the indicated temperatures on the hairy skin, while the solid line indicates the total number of thresholds for both glabrous and hairy skin combined. $A$, Pain thresholds in humans obtained from 19 subjects tested once on the hairy skin and from 8 of the 19 given a second test on the thenar eminence of the glabrous skin of the hand. $B$, Response thresholds of $\mathrm{CMH}$ nociceptors. $C$, Response thresholds of AMH nociceptors. jects, 9 tested on the arm and 6 others tested on the leg or foot $(p>0.5)$ and $(2)$ for the same 6 subjects randomly chosen and tested first on the arm and then given a second test on the foot $(p>0.5)$. Distributions of the response thresholds obtained from the $\mathrm{CMH}$ and $\mathrm{AMH}$ nociceptors in the monkey are shown in Figure 2, $B$ and $C$. The receptive fields of the CMHs were located either on the hairy $(n=21)$ or glabrous $(n=27)$ skin of the hand or hairy skin of the arm, leg, or foot $(n=10)$. The receptive fields of $31 \mathrm{AMHs}$ were located on the glabrous skin of the hand, and the remaining 14 AMHs were on the hairy skin of the hand $(n=9)$, arm, foot, or leg $(n=$ 5). A $t$ test revealed no significant differences in the response thresholds, obtained prior to the $\mathrm{CS}$, of $\mathrm{CMH}$ nociceptors located on the hairy as opposed to the glabrous skin $(p=0.45)$. Since the ranges of thresholds obtained for the arm, hand, and foot or leg were nearly identical, no further analyses of differences between regions of skin were performed.

Most of the small number of AMHs responsive to temperatures of $51^{\circ} \mathrm{C}$ or less had their receptive fields in hairy skin. The majority of the AMHs with thresholds of greater than $51^{\circ} \mathrm{C}$ were determined as responsive to heat only after subsequent tests at longer or higher stimulus temperatures delivered, at the end of experiments, with either the thermode or a hand-held probe.

It is readily apparent from Figure 2 that the CMHs, and not the AMHs, were sensitive to those temperatures that evoked threshold sensations of pain in humans and that this was the case both for glabrous and for hairy skin. Further, a median threshold of $45^{\circ} \mathrm{C}$ was obtained for hairy skin both for the CMHs and for pain sensation. Median thresholds of 45 and $43^{\circ} \mathrm{C}$ were found for CMHs 
and pain sensation, respectively, in glabrous skin. Thus, similar ranges and medians of threshold distributions in normal skin were found for pain sensation and for $\mathrm{CMH}$ nociceptors.

\section{The time course of changes in pain threshold in humans following injury by heat}

In the next experiment, we determined the time course of changes in the threshold by delivering a single test stimulus at selected points in time after the CS. The latter method avoided the temporal position effects of one test stimulus suppressing the pain elicited by another when multiple test stimuli were delivered repeatedly to the same spot on the skin. The results were useful as an aid in interpreting data obtained with the ascending temperature series of test stimuli given above and in all of our subsequent experiments.

In Figure 3 are the mean pain thresholds of 4 subjects tested on the volar forearm with a single stimulus before and after a $\mathrm{CS}$ of $50^{\circ} \mathrm{C}$ and $100 \mathrm{sec}$ duration. Within 0.5 min after the CS, the pain threshold was elevated by a mean of $5.5^{\circ} \mathrm{C}$ above control values ("hypoalgesia" or "suppression" of pain) followed by recovery from 2 to 2.5 min after the $\mathrm{CS}$ and a subsequent lowering of mean threshold to $2.5^{\circ} \mathrm{C}$ below control by $5 \mathrm{~min}$ ("hyperalgesia"). Thus, the time course of hypoalgesia following a mild heat injury was of relatively short duration and was replaced within about $3 \mathrm{~min}$ by the development of hyperalgesia. In this and subsequent experiments, spontaneous ratings of pain in the absence of a test stimulus were uncommon. When they did occur, they were after, but never before, the CS.

The testing of 3 subjects revealed that the recovery of

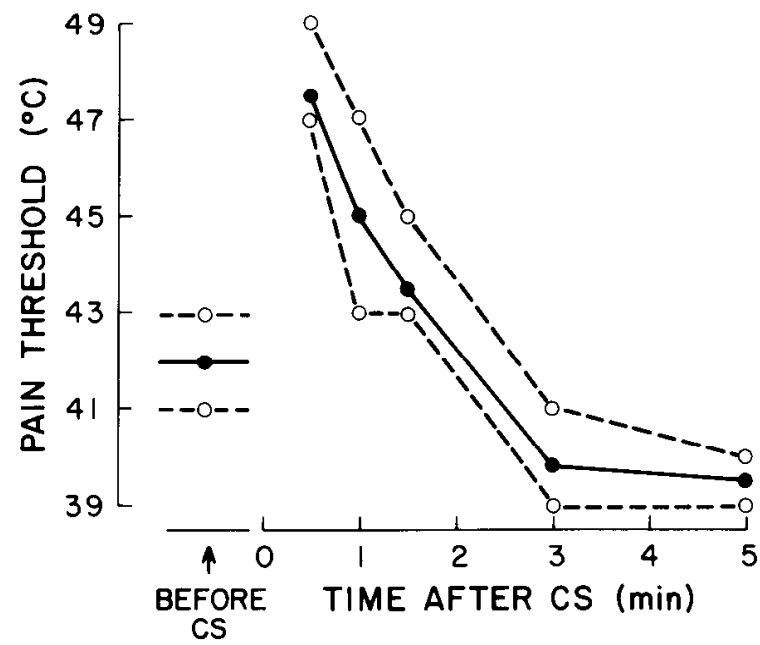

Figure 3. The time course of changes in the pain threshold following heat injury. Subjects were tested with a single test stimulus of $5 \mathrm{sec}$ duration before and after a conditioning stimulus (CS) of $50^{\circ} \mathrm{C}$ and $100 \mathrm{sec}$ duration. The temperature and time of occurrence of the heat stimulus was varied. The base temperature was $38^{\circ} \mathrm{C}$. The pain threshold was the minimal stimulus temperature evoking a rating of pain. The solid line connects the mean pain thresholds for 4 subjects, while the dashed lines above and below the solid line represent the highest and lowest thresholds, respectively, for these subjects at each point in time.

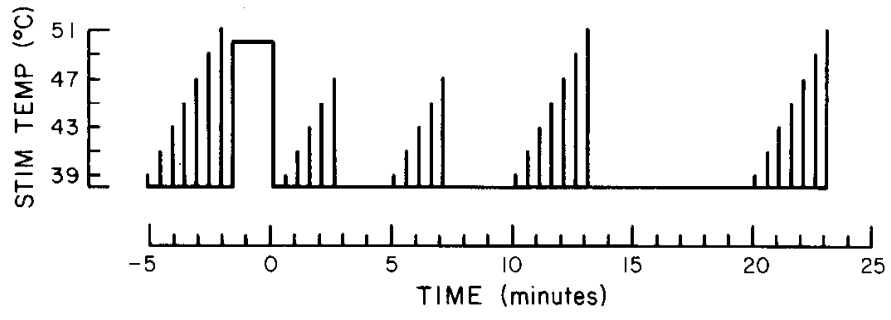

Figure 4. The standard test series of heat stimuli. Stimuli of 39 to $51^{\circ} \mathrm{C}$, each $5 \mathrm{sec}$ in duration, were delivered in ascending order of temperature in steps of $2^{\circ} \mathrm{C}$ on a base temperature of $38^{\circ} \mathrm{C}$ at interstimulus intervals of $25 \mathrm{sec}$ prior to heat injury from a conditioning stimulus (CS) of $50^{\circ} \mathrm{C}$ and 100 sec duration. Following the CS, stimuli of 39 to $47^{\circ} \mathrm{C}$ were given starting 0.5 min and again $5 \mathrm{~min}$ after the $\mathrm{CS}$. Stimuli of 39 to $51^{\circ} \mathrm{C}$ were delivered starting 10 and $20 \mathrm{~min}$ after the CS. The time of occurrence of each stimulus is referenced to the end of the CS $($ time $=0 \mathrm{~min})$.

pain thresholds to within 1 to $2^{\circ} \mathrm{C}$ of pre-CS values was achieved within 2 to $4 \mathrm{hr}$ after the CS. In contrast, the erythema produced by the CS often lasted several days.

A comparison of the changes in the median pain threshold following heat injury with parallel changes in the median response thresholds of heat-sensitive cutaneous receptors in the monkey

In the remaining experiments, we wished to measure the pain threshold and the response thresholds of high and low threshold heat-sensitive cutaneous receptors before and after heat injury using an identical sequence of heat stimuli as illustrated in Figure 4. Our first objective was to use this "standard" sequence of stimuli to determine the time course of the development of hyperalgesia following a CS of $50^{\circ} \mathrm{C}, 100 \mathrm{sec}$ delivered to the volar forearm. The second goal was to investigate which class of heat-sensitive receptors might account for the observed changes in the pain threshold.

In Figure $5 A$ is the time course of changes in the median pain threshold for 13 subjects tested on the volar forearm following a CS of $50^{\circ} \mathrm{C}, 100 \mathrm{sec}$. (The median was chosen over the mean since thresholds of many $\mathrm{AMH}$ and cold receptors were greater than $51^{\circ} \mathrm{C}$ and thus were not measured precisely.) All values are given for the times at which each ascending series of stimuli began (Fig. 4). Although pain thresholds varied over a wide range prior to the $\mathrm{CS}\left(41\right.$ to $\left.49^{\circ} \mathrm{C}\right)$, all were less than or equal to $43^{\circ} \mathrm{C}$ by $5 \mathrm{~min}$ after the $\mathrm{CS}$ and remained so through the last test at $20 \mathrm{~min}$. Four classes of cutaneous receptors were found to be responsive to heat: $\mathrm{CMH}$ and AMH nociceptors and the low threshold cold and warm receptors. The numbers and conduction velocities of each type of receptor in hairy and glabrous skin are given in Table I. Figure $5, B$ to $D$, summarizes the changes in the thresholds of the three types of cutaneous receptors whose responses to heat could be sensitized following a CS of $50^{\circ} \mathrm{C}, 60$ or $100 \mathrm{sec}$. Sensitization was defined as a lowering of the threshold below the control measured prior to the CS and/or an increase over the control in the number of impulses evoked by suprathreshold stimuli. The responses of warm receptors were suppressed but not sensitized following the CS and thus are 


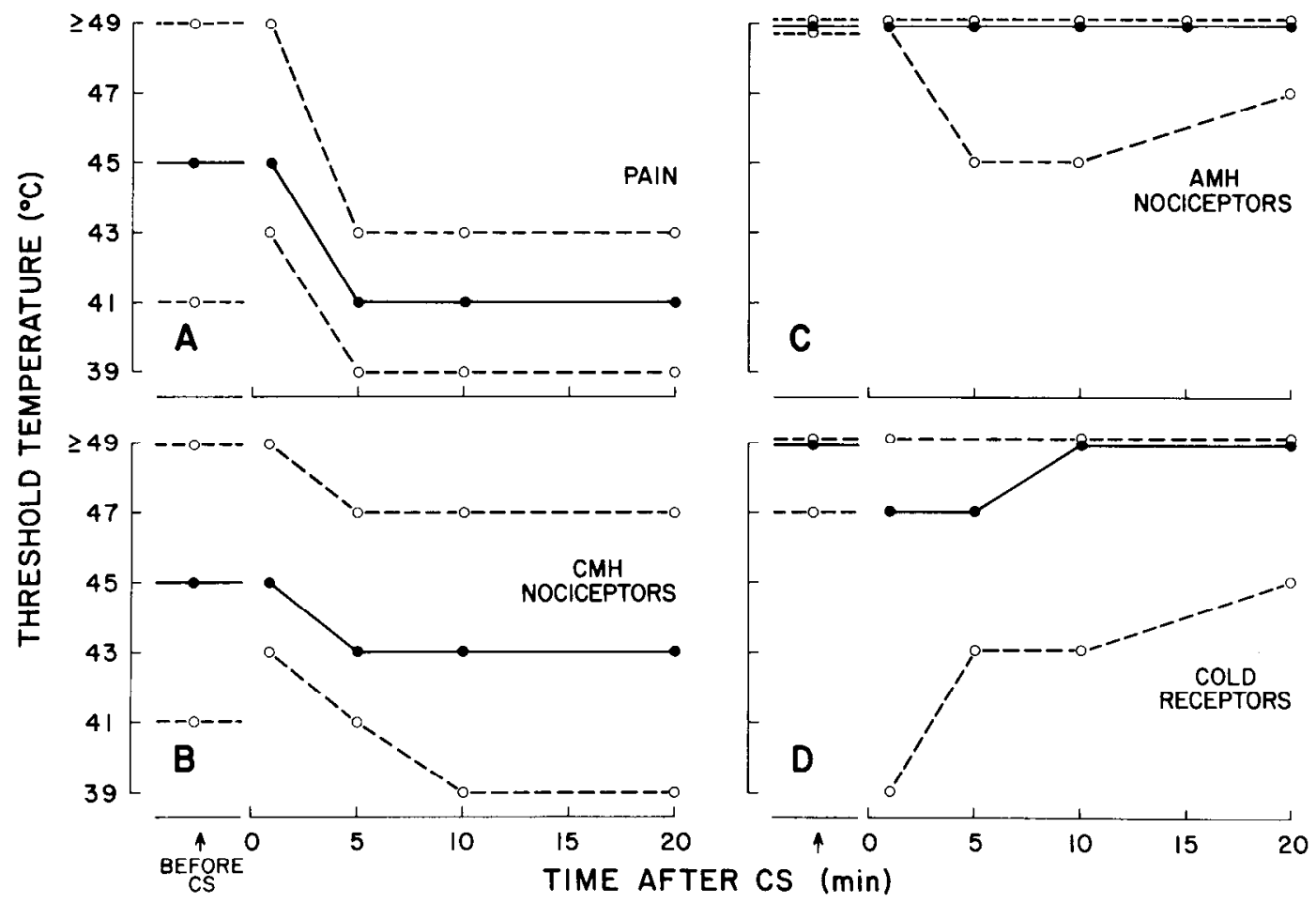

Figure 5. A comparison of the pain thresholds of humans, before and after heat injury, with the response thresholds of three types of monkey cutaneous receptors capable of being sensitized to heat. In each panel, the solid line connects the median thresholds, while the top and bottom dashed lines connect the highest and lowest individual thresholds obtained in response to the sequence of stimuli (see Fig. 4) beginning at each indicated time. Thresholds of $49^{\circ} \mathrm{C}$ or greater were pooled. $A$, Pain thresholds of human subjects tested on the volar forearm before and after heat injury by a conditioning stimulus (CS) of $50^{\circ} \mathrm{C}$ and 100 sec duration. $B$ and $C$, Response thresholds of CMH and $\mathrm{AMH}$ nociceptors, respectively, in monkey hairy skin. The CS was $50^{\circ} \mathrm{C}$ and either 60 or 100 sec. $D$, Response thresholds for the paradoxical response to heat of low threshold cold receptors in the monkey (data for hairy and glabrous skin combined). The CS was $50^{\circ} \mathrm{C}$ and either 60 or $100 \mathrm{sec}$.

TABLE I

Conduction velocities of the cutaneous afferents studied in the monkey

\begin{tabular}{lrcrcc}
\hline \multirow{2}{*}{$\begin{array}{c}\text { Receptor } \\
\text { Type }\end{array}$} & \multicolumn{2}{c}{ Hairy Skin } & & \multicolumn{2}{c}{ Glabrous Skin } \\
\cline { 2 - 3 } \cline { 5 - 6 } & Number & Mean $\pm \mathrm{SD}$ & & Number & Mean $\pm \mathrm{SD}$ \\
\hline & & $m / \mathrm{sec}$ & & $m / \mathrm{sec}$ \\
Warm & 3 & $0.9 \pm 0.1$ & 5 & $1.5 \pm 0.5$ \\
Cold & 5 & $10.7 \pm 0.7$ & & 4 & $11.2 \pm 1.1$ \\
CMH & 31 & $0.8 \pm 0.1$ & & 27 & $0.9 \pm 0.3$ \\
AMH & 14 & $15.0 \pm 7.0$ & & 31 & $22.2 \pm 13.0$ \\
\hline
\end{tabular}

${ }^{a}$ Low threshold warm and cold receptors and mechanoheat-sensitive nociceptors with $\mathrm{C}$ or A fibers (CMH and AMH, respectively).

not described in this figure. Two cold receptors in glabrous and two in hairy skin did not respond to any of the heat stimuli before or after the CS. Five cold receptors exhibited the "paradoxical" response to heat during testing prior to the CS and all but one of these were sensitized to heat following the CS as evidenced by a transient lowering of threshold over control by 2 to $6^{\circ} \mathrm{C}{ }^{6}$ However, the initial heat thresholds of these cold receptors were

\footnotetext{
${ }^{6}$ Because no apparent differences were observed in the response properties of this type of receptor in hairy versus glabrous skin nor in responses following a CS duration of 60 as opposed to $100 \mathrm{sec}$, data for both types of skin and both durations of CS were pooled.
}

higher than most pain thresholds, and the time course of sensitization did not parallel the time course of hypoand hyperalgesia. For example, recovery from sensitization was more rapid than recovery from hyperalgesia. The same statements apply to changes in response thresholds of $8 \mathrm{AMH}$ nociceptors with receptive fields on the hairy skin. These were given either a CS of $60(n=$ $5)$ or $100 \mathrm{sec}(n=3)$ with no apparent differences in results obtained due to these differences in CS duration. Three of the $8 \mathrm{AMHs}$ remained unresponsive to the heat stimuli used in the test sequence. The rest had a lowering of response thresholds from the initial values of $51^{\circ} \mathrm{C}$ to between 45 and $51^{\circ} \mathrm{C}$ followed by a recovery within 20 min. Not shown in the figure are similar results, but with still a lesser degree of sensitization, obtained from 15 AMHs in the glabrous skin. Of the latter, 3 exhibited a slight lowering of threshold, while the rest remained unresponsive to the test stimuli. Thus, sensitization was a more frequent occurrence of AMHs in hairy than in glabrous skin. However, the magnitude and time course of changes in the thresholds of AMHs in either type of skin, after the CS, did not parallel changes in pain threshold. In contrast, the time course of changes in the heat thresholds of $13 \mathrm{CMH}$ nociceptors in the hairy skin (Fig. $5 B$ ) closely paralleled that obtained for the pain thresholds following the same CS delivered to human skin. 
Furthermore, the range of $\mathrm{CMH}$ thresholds, at every point in time, overlapped or was equal to the range of pain thresholds. Also, sensitization was long lasting. In a few instances in which tests were given over a long period of time, sensitization was still present several hours after the CS. Thus, the time course and magnitude of changes in the pain threshold following the heat injury was matched only by changes in the heat thresholds of CMH nociceptors and not by those observed in any other type of heat-sensitive cutaneous receptor.

A striking feature of the pain thresholds was that the proportion of subjects reporting pain to stimuli of $43^{\circ} \mathrm{C}$ or less rose from about $50 \%$ prior to the CS to $100 \%$ by 5 min after the CS. Further, the mean magnitude ratings of pain elicited by a stimulus of $43^{\circ} \mathrm{C}$ increased following the CS (Fig. 6A). Analogous neuronal measures were obtained by the mean number of impulses evoked by the test stimulus of $43^{\circ} \mathrm{C}$ in each type of receptor in hairy skin before and after a $\mathrm{CS}$ of $50^{\circ} \mathrm{C}$. The $\mathrm{AMH}$ nociceptors were unresponsive to this stimulus both before and after the CS and therefore results for these receptors are not shown. All of the warm receptors responded maximally to the test stimulus prior to the CS but were suppressed, with varying degrees of recovery, following the CS (Fig. $6 C) .{ }^{6}$ Those cold receptors that subsequently responded to stimuli of $43^{\circ} \mathrm{C}$ or less following the CS did so only for a short period of time followed by a recovery to their previous levels of insensitivity (Fig. $6 D$ ). In contrast to the above, both the proportion of CMH nociceptors in hairy skin responsive to the test stimulus and the mean number of impulses evoked by the stimulus exhibited a decrease after the CS followed by an increase over preCS values (Fig. $6 B$ ). Thus, both the number of active $\mathrm{CMH}$ nociceptors and the magnitudes of their responses to a stimulus of $43^{\circ} \mathrm{C}$ underwent changes that paralleled those in threshold or near threshold ratings of pain in humans.

\section{The effects of a block of conduction in myelinated afferents on pain thresholds in humans before and after heat injury}

The fact that weak sensitization was observed in a small proportion of cold receptors and nociceptors with A fibers and the reported existence of AMHs with heat thresholds similar to those of CMHs (Dubner et al., 1977; Adriaensen et al., 1981) raised at least the possibility of a contribution of these receptors to alterations in the pain threshold following heat injury. In order to test this possibility, a compression block was applied at the wrist to the radial, median, and ulnar nerves (see "Materials and Methods"). The block resulted in the loss of touch and the sense of cool, the latter believed to be served by A $\delta$ fibers conducting within the range of 5 to $30 \mathrm{~m} / \mathrm{sec}$. The mean response latency of one subject to the first pain evoked mechanically with a sharp probe was measured before and after the compression block. The longer

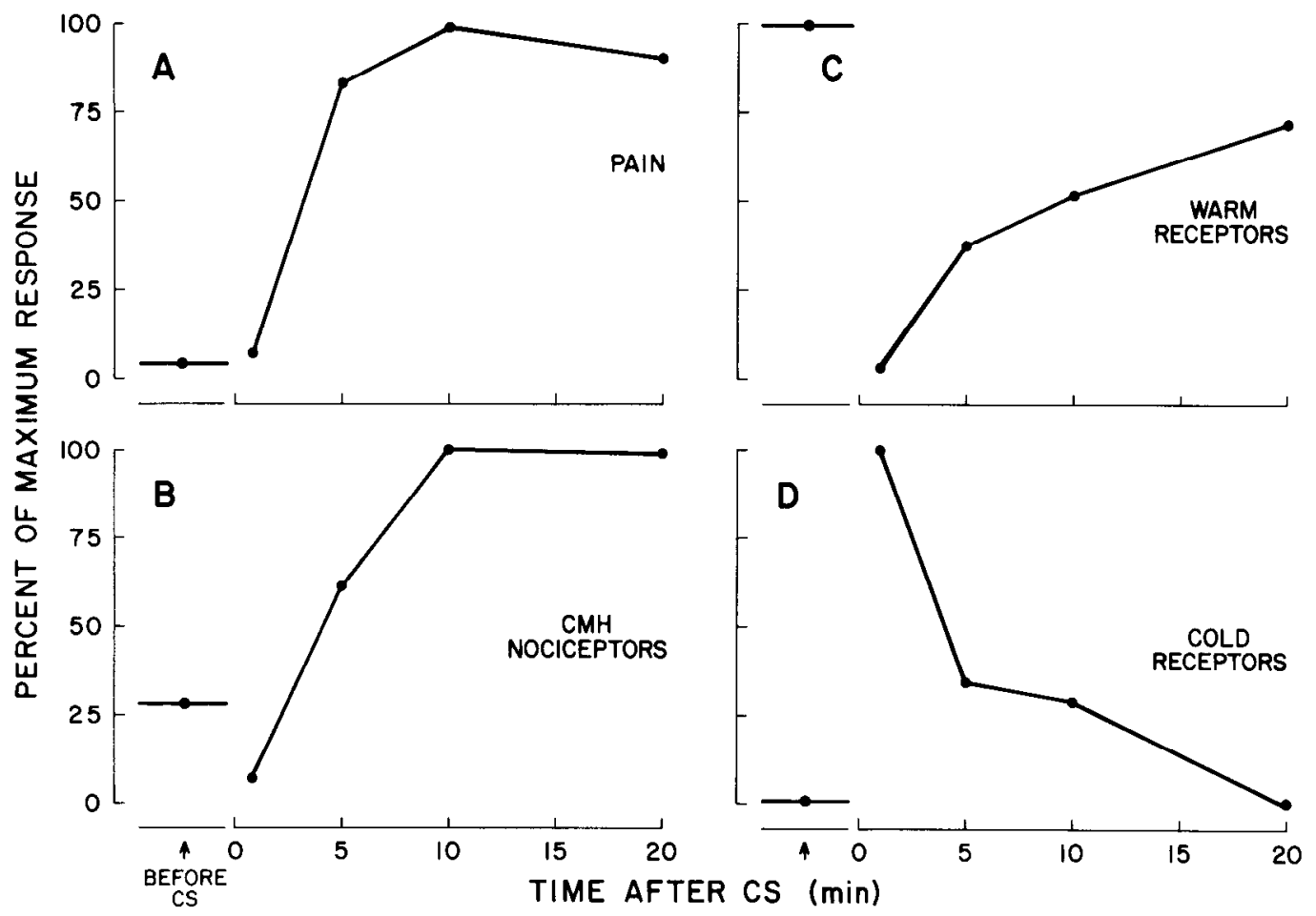

Figure 6. A comparison of the pain ratings of a test stimulus of $43^{\circ} \mathrm{C}$, before and after heat injury, with the magnitudes of neural responses evoked by the same stimulus in each of three types of cutaneous receptors. $A$, Magnitude ratings of pain, averaged for 13 subjects and expressed as a percentage of the maximum mean response to the test stimulus, were obtained before and after a $\mathrm{CS}$ of $50^{\circ} \mathrm{C}, 100 \mathrm{sec}$ duration. $B$, The mean number of impulses evoked by the test stimulus in 13 CMH nociceptors in monkey hairy skin. The mean is expressed as a percentage of the maximum obtained in response to the test stimulus. The $\mathrm{CS}$ was $50^{\circ} \mathrm{C}, 100 \mathrm{sec}$. $C$ and $D$, The mean number of impulses (percentage of maximum) evoked by the test stimulus in 8 warm and 9 cold receptors in the monkey. The CS was $50^{\circ} \mathrm{C}$ and either 60 or $100 \mathrm{sec}$ duration. 
latency obtained following the block was consonant with a loss of conduction in A fibers. In previous studies using this kind of compression block, microneurographic recordings have shown that impulse conduction in myelinated fibers was blocked at the time when sensations of touch and cold were abolished and only $\mathrm{C}$ fibers were conducting (Torebjörk and Hallin, 1973; MacKenzie et al., 1975; Hallin and Torebjörk, 1976).

The A fiber block involved most of the hand, thereby reducing or eliminating the possibility that nociceptors with myelinated afferents in the superficial radial nerve or in nerves with overlapping distributions might be activated by the heat stimuli. In addition, the compression block did not result in any obvious impairment of circulation to the hand.

Following the first indication of a successful block, 8 subjects were tested prior to and up to $10 \mathrm{~min}$ after a CS of $50^{\circ} \mathrm{C}, 100 \mathrm{sec}$. The pain thresholds obtained under the block were entirely within the range of values obtained for the 13 subjects tested on the forearm without a block (Fig. 7). The same was true for the pain ratings of all suprathreshold stimuli. That is, the A fiber block produced no obvious changes in psychophysical functions relating stimulus temperature to maximum ratings of pain (R. H. LaMotte, J. G. Thalhammer, H. E. Torebjörk, and C. J. Robinson, unpublished observations). These findings confirm the hypothesis that the phenomena of hypo- and hyperalgesia following a mild heat injury are served by activity in $\mathrm{C}$ fibers and not $\mathrm{A}$ fibers. The possibility of conduction in A fibers of the smallest diameter cannot be ruled out by the above experiment. However, this is ruled out for most AMHs with heat thresholds similar to those of CMHs since the mean conduction velocities of these more sensitive AMHs are typically in the range of 15 to $20 \mathrm{~m} / \mathrm{sec}$ (Dubner et al., 1977; Adriaensen et al., 1981)-values greater than that

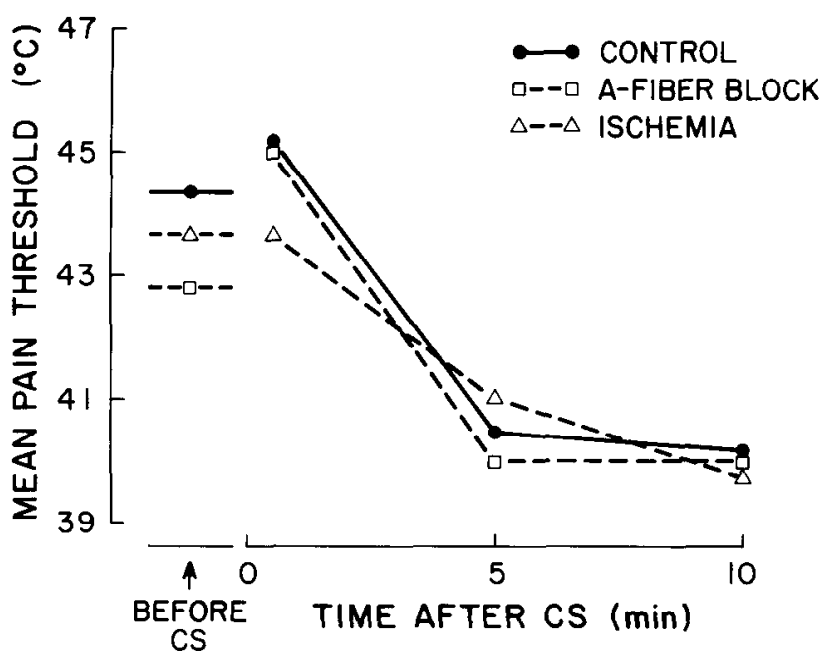

Figure 7. Results demonstrating that alterations in pain thresholds following heat injury did not depend upon either blood flow or conduction in A fibers. The mean pain threshold before and after heat injury by a CS of $50^{\circ} \mathrm{C}, 100$ sec was determined (1) during a compression block of conduction in the A fibers in 8 subjects $(\square),(2)$ during ischemia induced by a pressure cuff in 3 subjects $(\triangle)$, and (3) under control conditions in 13 subjects $(\mathbf{O})$. of the low threshold cold receptors (Darian-Smith et al., 1973; Dubner et al., 1975).

\section{The effects of ischemia on pain thresholds in humans before and after heat injury}

In 3 subjects, a pressure cuff was applied to the upper arm and inflated to $200 \mathrm{~mm} \mathrm{Hg}$, thereby eliminating blood flow to the forearm. The cuff was applied only for the $\sim 20$ min required to test the pain threshold prior to and up to $10 \mathrm{~min}$ after a $\mathrm{CS}$ of $50^{\circ} \mathrm{C}, 100 \mathrm{sec}$. Thus, there was no significant block of conduction in A fibers as in the previous experiment. No apparent differences were observed between the results obtained from these subjects and those obtained from the 13 subjects tested on the forearm when circulation was intact (Fig. 7). Both hypo- and hyperalgesia were observed under ischemia, suggesting that these phenomena do not occur as a result of regional changes in blood flow that might occur following heat injury. These results are consistent with those of Lynn (1979, 1980) who demonstrated that neither decreases in the pain threshold in humans nor the sensilization of $\mathrm{CMH}$ nociceptors in the rabbit depended on local blood flow.

These results do not mean that the rate of blood flow plays no role in the pain elicited during and following heat injury. On the contrary, the results of a pilot study (R. H. LaMotte, J. G. Thalhammer, H. E. Torebjörk, and C. J. Robinson, unpublished observations) suggested that intense hyperemia induced by circulating warm water through a tube coiled around the arm reduced the injurious and hyperalgesic effects of the CS. Conversely, ischemia produced by a rubber band wrapped around the base of a finger, while not greatly altering the time course or magnitude of hyperalgesia on the finger pad, resulted in a remarkable increase in the magnitude ratings of pain with time during the CS. Nevertheless, the results of the ischemic forearm study demonstrate that the lowering of the pain threshold following the CS did not result from or depend upon alterations in blood flow that might have occurred, for example, due to the release of vasoactive substances within the area of injury.

\section{Differences for hairy and glabrous skin in the changes in pain thresholds in humans and response thresholds of CMH nociceptors in monkeys following a heat injury}

The changes in mean pain thresholds, following the $\mathrm{CS}$, for hairy skin of the forearm were compared with those for three regions of the glabrous skin of the hand (Fig. 8, left panel). In order to evaluate the differences for these areas of skin in the changes in threshold following heat injury, thresholds obtained at each time aftcr the $\mathrm{CS}\left(50^{\circ} \mathrm{C}, 100 \mathrm{sec}\right)$ were first expressed as percentages of the subject's threshold prior to the CS. Then, repeated measures analyses of variance were made of the differences between the subjects' percentage scores for the hairy skin and those for the finger and the thenar eminence of the glabrous skin. ${ }^{7}$ Significantly greater decreases in the pain threshold were found for the hairy

\footnotetext{
${ }^{7}$ The results of these and all of our analyses of variance with repeated measures over time indicated a highly significant main effect of the time of testing $(p<0.001)$.
} 


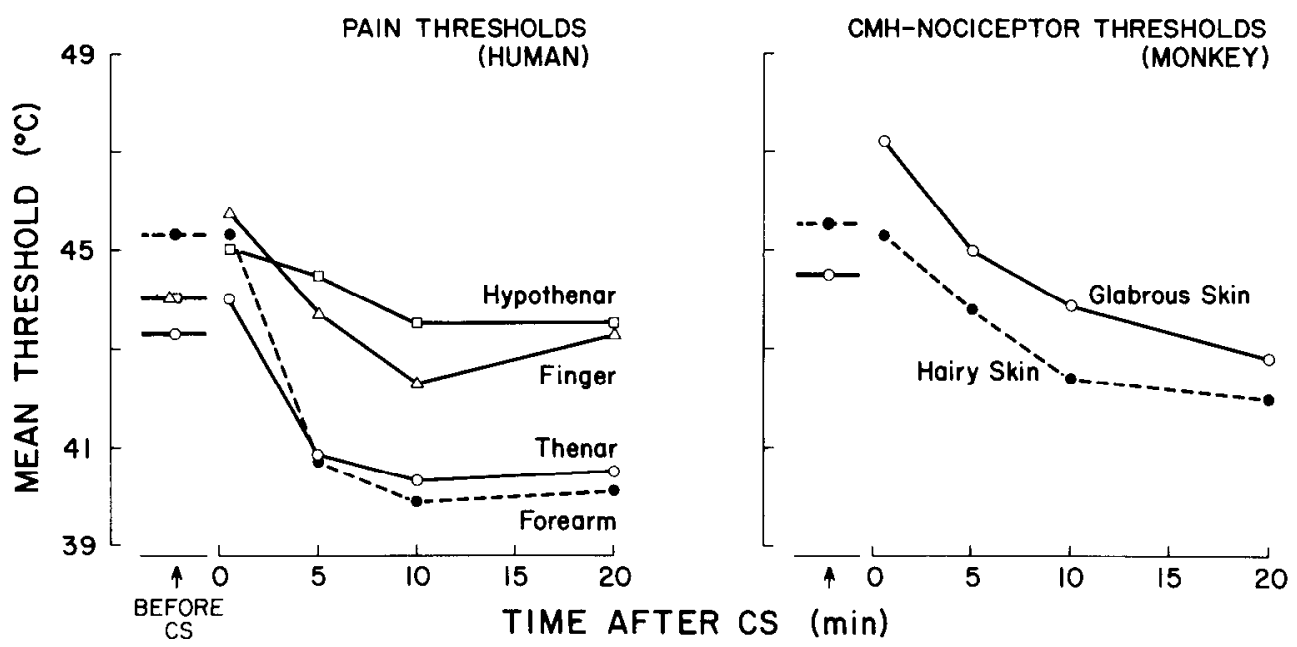

Figure 8. A comparison of alterations in the thresholds in glabrous skin with those in hairy skin following a heat injury (CS). Left panel, Mean pain thresholds of 8 subjects tested first on the hairy skin of the forearm (dashed line) and subsequently on the glabrous skin (solid lines) of the thenar eminence ( 8 subjects, $\bigcirc$ ), fingertip ( 6 subjects, $\Delta$ ), and hypothenar eminence (4 subjects, $\square$ ). Right panel, Mean response thresholds of CMH nociceptors in monkey, 11 on the glabrous skin (solid line) and 13 on the hairy skin (dashed line). In both panels, the CS was $50^{\circ} \mathrm{C}, 100 \mathrm{sec}$.

skin than for either the finger $(p=0.006)$ or the thenar eminence $(p<0.001)$. Although thresholds on the thenar eminence were about the same as those on the hairy skin 5 to 20 min after the CS, they were significantly lower prior to the CS and thus exhibited less of a decrease. Thresholds on the finger and hypothenar eminence were the same as those on the hairy skin prior to the CS but were higher after the CS. The least lowering of the pain threshold occurred on the hypothenar eminence. In fact, 3 of the 4 subjects tested on this area exhibited no lowering of the threshold, only a transient elevation following the CS.

Similar analyses were made on the $\mathrm{CMH}$ response thresholds, obtained after the CS, each expressed as a percentage of the threshold obtained prior to the CS. A significantly lesser degree of threshold lowering was observed for the $11 \mathrm{CMH}$ nociceptors tested on the glabrous skin than for the $13 \mathrm{CMHs}$ studied on the hairy skin ( $p$ $=0.01$ ). Although small sample sizes precluded further statistical analyses of the regional differences within glabrous skin, no apparent differences in thresholds were observed for CMHs with receptive fields on the thenar eminence as opposed to the hypothenar eminence, finger, or palm. In any case, it is clear that following a mild heat injury to the skin, a greater sensitization of $\mathrm{CMH}$ nociceptors and a greater degree of hyperalgesia (lowering of the pain threshold) occurred for the hairy skin than for the glabrous skin.

The effects of variations in the duration and intensity of the CS on the time course of changes in pain thresholds in humans and response thresholds of CMH nociceptors in the monkey

In order to determine whether the test stimuli themselves might alter the thresholds of CMHs in the monkey, $4 \mathrm{CMHs}$ were given the standard sequence of test stimuli (Fig. 4) without presentation of the CS. Only slight suppression and not sensitization was observed during a subsequent 20-min period of testing. Following a subse- quent presentation of the CS, sensitization ensued. Analogous psychophysical experiments in which stimuli of 5 sec duration and temperatures of 47 to $50^{\circ} \mathrm{C}$ were presented revealed only a transient suppression of the pain ratings elicited by subsequent test stimuli (LaMotte, 1979). Thus, it was considered unlikely that the presentation of the ascending series of stimuli in the present study contributed to the development of hyperalgesia following the $\mathrm{CS}$ of $50^{\circ} \mathrm{C}$.

The effects of variations in the duration of a CS of $50^{\circ} \mathrm{C}$ on the pain thresholds and response thresholds of CMHs also were studied. A comparison was made between the alterations in thresholds following a $\mathrm{CS}$ of $50^{\circ} \mathrm{C}, 60 \mathrm{sec}$ duration and those following a CS of $50^{\circ} \mathrm{C}$, $100 \mathrm{sec}$ duration. The results obtained from 4 human subjects tested once under each CS duration on the volar forearm are compared in Figure 9 with the results obtained for hairy skin from the $13 \mathrm{CMH}$ nociceptors tested following a CS of $100 \mathrm{sec}$ and 7 other CMHs tested after a CS of $60 \mathrm{sec}$ duration. The data from both sets of experiments are suggestive of lower thresholds following the longer duration of CS. However, the differences in thresholds obtained under the two durations of CS failed to reach statistical significance in repeated measures analyses of variance. This was true both for the pain thresholds $(p=0.16)$ and for CMH response thresholds $(p=0.24)$. Either larger differences in CS duration or larger sample sizes might be required to reveal a statistically significant effect of differences in CS duration on the thresholds for pain and $\mathrm{CMH}$ responses.

Lastly, a test of the effects of differences in the intensity of the CS on changes in the pain threshold was conducted. In a few psychophysical experiments, a CS of either $53^{\circ} \mathrm{C}$ for $30 \mathrm{sec}$ for $48^{\circ} \mathrm{C}$ for $320 \mathrm{sec}$ was delivered to the volar forearm or foot. These stimuli have approximately the same injurious effects on the skin as does our $\mathrm{CS}$ of $50^{\circ} \mathrm{C}, 100 \mathrm{sec}$ (Moritz and Henriques, 1947). The time course of hypo- and hyperalgesia did not differ for these three types of CS. Thus, it is likely that there is a 
trade off between the duration and intensity of the minimal stimulus required to induce hyperalgesia as there is to produce an irreversible injury of the skin.

A comparison of the distributions of pain thresholds in humans with the distributions of response thresholds of $\mathrm{CMH}$ nociceptors in monkeys before and after heat injury

Although the time course of the sensitization of $\mathrm{CMH}$ nociceptors paralleled the time course of the develop-

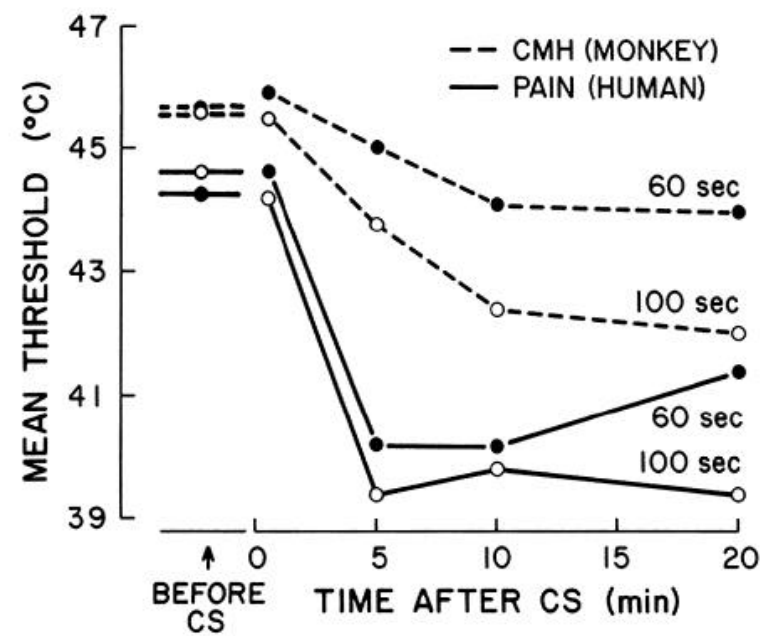

Figure 9. The effects of differences in the duration of CS on alterations in the pain thresholds in humans and the response thresholds in $\mathrm{CMH}$ nociceptors in the monkey. Mean pain thresholds (solid lines) were determined for 4 humans tested on the forearm before and after a CS of $50^{\circ} \mathrm{C}$ and $60 \mathrm{sec}(\mathbf{O})$ or $100 \mathrm{sec}(\mathrm{O})$. Mean response thresholds for hairy skin were obtained from $13 \mathrm{CMHs}$ tested before and after a 100 -sec CS of $50^{\circ} \mathrm{C}(\mathrm{O})$ and 7 other $\mathrm{CMHs}$ before and after a 60 -sec CS of $50^{\circ} \mathrm{C}(\mathbf{O})$. ment of hyperalgesia after heat injury, the magnitudes of change in the mean or median thresholds in the two sets of experiments were not the same. An appropriate question is whether the magnitudes of change in at least some of the nociceptors matched the magnitades of change in the pain thresholds of some of the subjects. A summary of the distributions of human pain thresholds and monkey $\mathrm{CMH}$ response thresholds for the arm are presented in Figure 10. The mean pain threshold shows a slightly greater drop from normal to hyperalgesic skin than does the mean threshold of $\mathrm{CMH}$ nociceptors in the monkey. However, the development of an increased sensitivity to pain elicited by lower temperature stimuli, such as $39^{\circ} \mathrm{C}$, is matched at 10 and 20 min after the CS by the development of a sensitivity to such stimuli in a small number of $\mathrm{CMH}$ nociceptors-a sensitivity that they did not have in normal skin.

Another similarity between pain thresholds and $\mathrm{CMH}$ thresholds that was not evident in comparisons of means was that subjects and nociceptors with thresholds of less than $45^{\circ} \mathrm{C}$ prior to the CS (indicated by the shading in Fig. 10) had elevated thresholds at $0.5 \mathrm{~min}$ after the CS, while those with thresholds equal to or greater than $45^{\circ} \mathrm{C}$ did not. This effect may be attributed to the nature of the ascending sequence of stimulus temperature and to the finding that both hypoalgesia and the decrease in nociceptor sensitivity immediately following the CS were short lived (e.g., see Fig. 3): responses to lower temperatures were tested sooner and thus suppressed more than responses to higher temperatures.

There is a slight mismatch in the time course of changes in pain thresholds and $\mathrm{CMH}$ response thresholds. Although 4 humans had pain thresholds of $39^{\circ} \mathrm{C}$ when tested 5 min after the $\mathrm{CS}$, no $\mathrm{CMHs}$ responded to this stimulus at this time. Possibly minor discrepancies

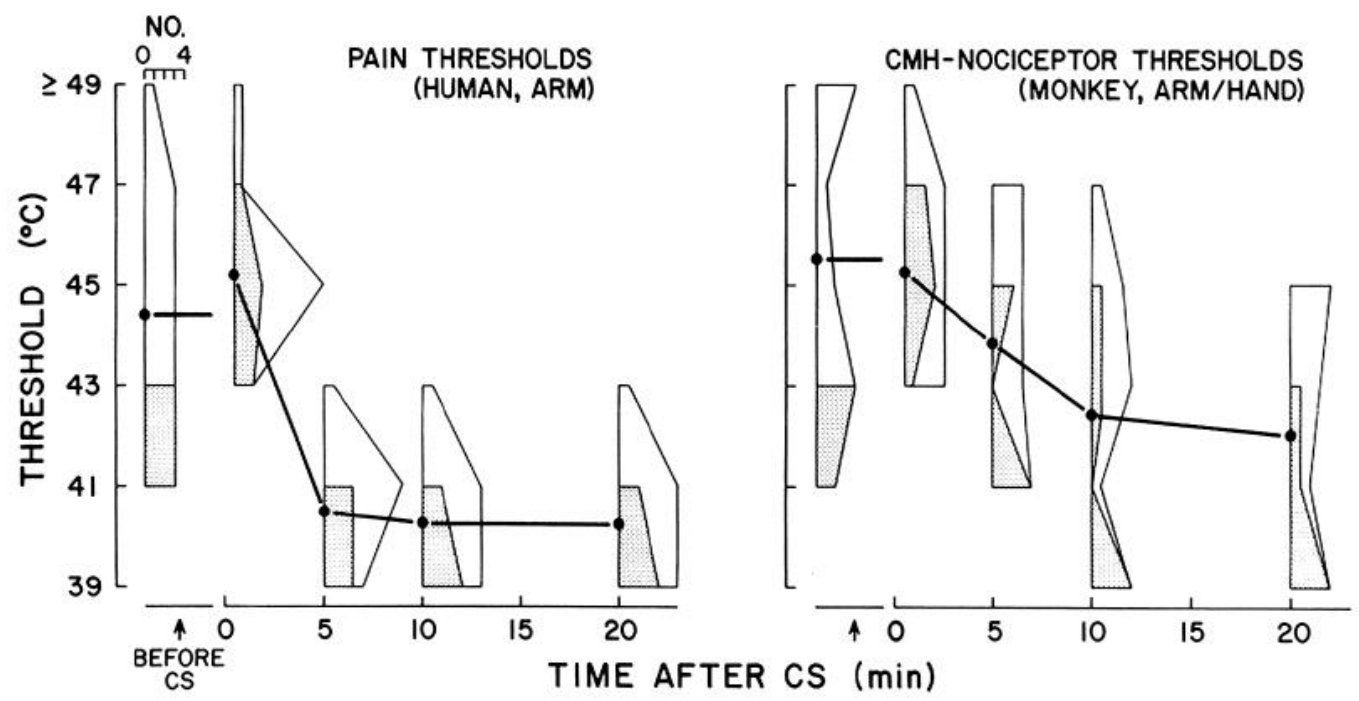

Figure 10. The time course of changes in the distributions of pain thresholds in humans and response thresholds of $\mathrm{CMH}$ nociceptors in monkeys following a heat injury (CS). The number (No.) of human subjects or $\mathrm{CMH}$ nociceptors having the indicated threshold temperature is represented by the width of the histogram at each threshold temperature. Thresholds of $49^{\circ} \mathrm{C}$ or greater were pooled. The shaded areas indicate the thresholds of subjects or CMH nociceptors whose initial thresholds, prior to the CS, were less than or equal to $43^{\circ} \mathrm{C}$. The solid circles connected by the heavy line are the mean thresholds. The $\mathrm{CS}$ was $50^{\circ} \mathrm{C}, 100 \mathrm{sec}$. Left panel, Pain thresholds of 13 humans tested on the volar forearm. Right panel, Response thresholds of $13 \mathrm{CMH}$ nociceptors tested on the hairy skin of the arm or hand in monkey. 
such as this would be less apparent if a larger sample of CMHs were studied.

The suppressive effects of the base stimulus on pain threshold. In order to test the possibility that the base temperature of $38^{\circ} \mathrm{C}$ had a mild suppressive effect on the thresholds, a psychophysical study was conducted in which stimulus increments were presented on a base temperature of $30^{\circ} \mathrm{C}$. 'Test stimuli were delivered to the volar forearms of 3 subjects in steps of $2^{\circ} \mathrm{C}$ in order of ascending temperature from 31 to $47^{\circ} \mathrm{C}$ before and at 10 min after a $\mathrm{CS}$ of $50^{\circ} \mathrm{C}, 100 \mathrm{sec}$. Following the $\mathrm{CS}$, the base was elevated from 30 to $38^{\circ} \mathrm{C}$ and maintained at this value until $10 \mathrm{~min}$ after the $\mathrm{CS}$. (This was done to allow the development of hyperalgesia to occur under the same base temperature as used in our other experiments.) At $10 \mathrm{~min}$ after the $\mathrm{CS}$, the base was reduced to $30^{\circ} \mathrm{C}$ and the ascending temperature sequence began. The mean pain threshold dropped by $7^{\circ} \mathrm{C}$ from $45^{\circ} \mathrm{C}$, obtained in all 3 subjects prior to the $\mathrm{CS}$, to $38^{\circ} \mathrm{C}$ (range of 37 to $39^{\circ} \mathrm{C}$ ) $10 \mathrm{~min}$ after the CS. In the previous tests with the standard test series given on a base of $38^{\circ} \mathrm{C}$, subjects with pre-CS thresholds of $45^{\circ} \mathrm{C}$ had a mean decrease in pain threshold of only $4.5^{\circ} \mathrm{C} 10 \mathrm{~min}$ after the CS. These results are suggestive of a mild suppressive effect of the $38^{\circ} \mathrm{C}$ base on the pain threshold following the CS.

A greater suppressive effect of the base stimulus on lower than on higher thresholds following the CS would bring the thresholds of different individuals closer together. In fact, the standard deviation of pain thresholds for the volar forearm decreased from $2.6^{\circ} \mathrm{C}$ (prior to the CS) to values of 1.2 to $1.5^{\circ} \mathrm{C}$ obtained 0.5 to $20 \mathrm{~min}$ after the CS. Similarly, the standard deviation of CMH thresholds for monkey hairy skin decreased from $3.6^{\circ} \mathrm{C}$ prior to the CS to post-CS values of 2.0 to $2.8^{\circ} \mathrm{C}$.

A comparison of the distributions of pain thresholds in humans with the distributions of response thresholds of CMH nociceptors also obtained in humans before and after heat injury

The standard test series of test stimuli was delivered to the cutaneous receptive fields of $14 \mathrm{CMH}$ nociceptive afferents recorded percutaneously from the peroneal nerve in the awake human subject. The mean conduction velocity, as obtained from 8 of the 14 was $0.85 \pm 0.17 \mathrm{~m} /$ sec. Eight CMHs were studied before and up to $10 \mathrm{~min}$ after the CS and only data for these are included in the present study. Receptive fields of these CMHs were located on the dorsum of the foot $(n=4)$ or the leg $(n$ $=4)$. The $\mathrm{CS}$ was either $50^{\circ} \mathrm{C}$ for $100 \mathrm{sec}(n=5)$ or 60 $\sec (n=1)$ or $48^{\circ} \mathrm{C}$ for $320 \mathrm{sec}(n=2)$ (see "Materials and Methods"). The psychophysical measurements obtained for these different types of CS were virtually identical and no apparent differences in the responses of CMH nociceptors could be readily explained on the basis of which CS was delivered. Pain thresholds were obtained from 11 subjects during the first test on the foot or leg regardless of whether a simultaneous recording was also being carried out. Thus, each pain threshold was obtained from a different observer, whereas $2 \mathrm{CMH}$ nociceptors were recorded on different occasions from the same subject and the rest were from different subjects. The distributions of pain thresholds on the leg or foot before and after the CS are shown in Figure 11 (left panel). As stated earlier, pain thresholds on the foot or leg were not significantly different from those on the forearm prior to the CS. The overall time course of hypoand hyperalgesia for the leg or foot matched that found for the forearm (compare with Fig. 10). The standard deviation of pain thresholds decreased from $2.5^{\circ} \mathrm{C}$, obtained prior to the $\mathrm{CS}$, to post-CS values of 1.8 to $2.1^{\circ} \mathrm{C}$. Pain thresholds of subjects with lower initial thresholds (less than $45^{\circ} \mathrm{C}$ ) were elevated more and for a longer time immediately after the CS than those of subjects with higher initial thresholds.

The range of heat thresholds of $\mathrm{CMH}$ nociceptors on the human leg or foot prior to the CS was 41 to $43^{\circ} \mathrm{C}$ ( $n$ $=14$ ). This is in contrast to the much wider range of values obtained from $\mathrm{CMHs}$ in the monkey. The $8 \mathrm{CMHs}$ in humans that were studied both before and after the CS all happened to have a threshold of $41^{\circ} \mathrm{C}$. It is interesting that these more sensitive $\mathrm{CMHs}$ in humans were suppressed following the CS in the manner characteristic of the more sensitive CMHs in the monkey and the more sensitive subjects in the psychophysical experiments. However, only 2 of the CMHs in human exhibited a lowering of the threshold below control following the CS. Of the monkey CMHs with pre-CS thresholds of $41^{\circ} \mathrm{C}$, both were suppressed after the CS and one remained so to the end of testing. Thus, there were similarities in the time course of changes in the response thresholds of CMHs in monkeys and humans following heat injury despite the differences in the mean magnitude of these changes for the two species. Also, the time course of changes in the pain threshold was similar for the forearm and the leg or foot.

\section{Discussion}

\section{The quality of heat-pain sensation}

Subjects questioned at the end of the experiments stated that the pain evoked by a heat stimulus had a singular quality of burning or stinging which increased in magnitude to a single maximum followed by a decrease and disappearance. There were no reports of a double sensation (i.e., "first" or "pricking" pain followed by a second pain of burning) at least when stimuli were presented in ascending order of magnitude. However, some subjects reported a pricking, or "prickle" sensation during the experiment in which a single stimulus of 41 to $45^{\circ} \mathrm{C}$ was presented (Fig. 3). Other studies have reported double pain and/or short latency sensations of pricking pain, but these sensations typically have been elicited by heat applied at long interstimulus intervals to hairy skin. In one study, a short latency pricking pain sensation was evoked by a single stimulation of $43^{\circ} \mathrm{C}$ delivered to the hairy skin but not by stimuli of 43 to $51^{\circ} \mathrm{C}$ delivered to the glabrous skin (Campbell and LaMotte, 1977). For glabrous skin, a double pain sensation requires stimulus temperatures of greater than $51^{\circ} \mathrm{C}$ (Campbell and LaMotte, 1977; J. G. Thalhammer and R. H. LaMotte, unpublished observations). For hairy skin, a small number of AMH nociceptors responsive to stimuli of less than $47^{\circ} \mathrm{C}$ has been found in monkeys (Dubner et al., 1977) and humans (Adriaensen et al., 1981) and may serve the 


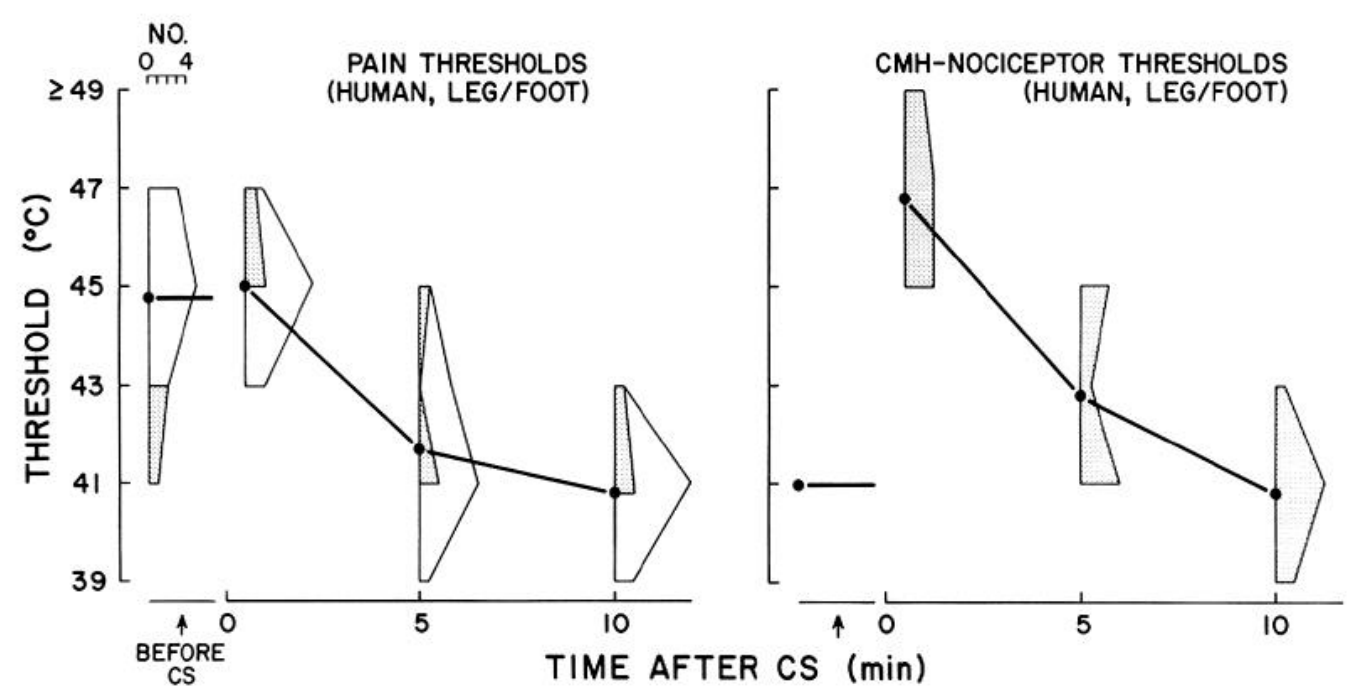

Figure 11. The time course of changes in the distributions of pain thresholds and response thresholds of $\mathrm{CMH}$ nociceptors in humans following a heat injury (CS) delivered to the hairy skin of the leg or foot. Left panel, Pain thresholds of 11 humans. Right panel, Response thresholds of 8 $\mathrm{CMH}$ nociceptors recorded from the peroneal nerve in the awake human subject (not necessarily the same subjects contributing to the data in the left panel). The same format as in Figure 10 is used.

sense of pricking pain. Since these nociceptors appear more responsive to innocuous heat stimuli below $45^{\circ} \mathrm{C}$ than are the CMHs, it is possible that when stimuli are presented in ascending order of magnitude, the responses of these AMHs are somewhat suppressed before the pain threshold is reached, thereby explaining the absence of double pain sensations under these stimulus conditions. In any case, the fact that, in normal and in hyperalgesic skin, pain thresholds did not appear altered following a conduction block in A fibers indicates that the contribution from AMHs was not of critical importance.

\section{Pain thresholds in normal skin}

In the present study, pain thresholds prior to the CS ranged from 41 to $49^{\circ} \mathrm{C}$. The only regional difference found between glabrous and hairy skin was a slightly lower mean threshold on the thenar eminence than on the volar forearm. No other differences were noted between the pain thresholds for forearm, leg, foot, hypothenar eminence, and fingertip. Previous investigations using heat stimulation also have found only minor differences in the pain thresholds between most loci on the body (Hardy et al., 1952; Lynn and Perl, 1977).

Contributions from cutaneous receptors. In both monkeys and humans, only the CMH nociceptors had threshold sensitivities within the range of pain thresholds in humans. In the monkey, the response thresholds of most AMHs and cold receptors were outside of this range of pain thresholds. Conversely, thresholds of warm receptors were well below the pain threshold and warm receptors responded as well or better to painless heat than to painful heat. Percutaneous nerve recordings in humans have indicated that the response properties of low threshold cold and warm receptors (Hensel and Boman, 1960; Konietzny and Hensel, 1975) and AMH nociceptors (Adriaensen et al., 1981) are similar in most respects to those studied in the same receptors in monkeys (Iggo, 1969;
Hensel and Iggo, 1971; Darian-Smith et al., 1973; Sumino et al., 1973; Dubner et al., 1975, 1977; Kenshalo and Duclaux, 1977; Darian-Smith et al., 1979).

In the present study, CMHs in humans had thresholds of 41 to $43^{\circ} \mathrm{C}$, whereas those of most CMHs in the monkey lay between 41 and $49^{\circ} \mathrm{C}$. It is possible that the thresholds of CMHs and the more sensitive AMHs are distributed over lower temperature values in humans than in monkeys. Alternatively, the disproportionate number of lower threshold CMHs in humans, in comparison with that observed in the monkey (e.g., Beitel and Dubner, 1976b; LaMotte and Campbell, 1978), may be due to our use of weaker and more superficial mechanical stimuli (gentle scraping) to search for $\mathrm{CMH}$ activity in humans as opposed to our pinching the skin in the monkey experiments (see "Materials and Methods"). We have found a positive correlation between the heat thresholds and mechanical thresholds of CMHs in the monkey (J. G. Thalhammer and R. H. LaMotte, unpublished observations), leading us to speculate that a weaker mechanical search stimulus may have yielded CMH nociceptors with lower heat thresholds. Further, a recent study by Van Hees and Gybels (1981) has found thresholds of CMHs in humans to vary from about 40 to $47^{\circ} \mathrm{C}$. We therefore favor the hypothesis that $\mathrm{CMH}$ thresholds on the leg or foot in humans are, in reality, similar to those that we have found for the monkey arm, leg, and foot.

Most neurophysiological studies of CMHs in the monkey have obtained heat thresholds within close range of those obtained for monkey CMHs in the present study (41 to $51^{\circ} \mathrm{C}$ ) despite differences in the base (adapting) temperatures and the intensities, durations, and presentation rates of test stimuli used and whether glabrous or hairy skin was tested (Beitel and Dubner, 1976b; Croze et al., 1976; Georgopoulos, 1976; Kumazawa and Perl, 1977). Similar ranges also have been obtained for monkey 
spinothalamic and trigeminothalamic neurons of the type that receives input from CMHs (Christensen and Perl, 1970; Kenshalo et al., 1979; Price et al., 1976, 1978) and for monkey ventral posterior lateral thalamic neurons that receive input from dorsal horn neurons (Kenshalo et al., 1980). Thus, the evidence suggests that the threshold sensitivities of $\mathrm{CMH}$ nociceptive afferents in the monkey are preserved in the parallel sensitivities of the higher order neurons to which they project and that these, in turn, are matched by thresholds for pain as measured in humans.

Changes in pain thresholds following a mild heat injury. The similarities in the time course and magnitude of changes in pain thresholds in humans and changes in heat thresholds of $\mathrm{CMH}$ nociceptors in monkeys and humans following mild heat injury suggest that $\mathrm{CMH}$ activity provides a peripheral neuronal basis for hypoand hyperalgesia. Threshold sensitivities of other heatsensitive cutaneous receptors, such as AMH nociceptors and low threshold warm and cold receptors, did not undergo changes that paralleled those observed for pain sensation. 'The responses of warm fibers following heat injury were greatly suppressed with gradual and less than complete recovery occurring over a 20 -min period of testing. Only a small proportion of AMHs and cold receptors were appreciably sensitized following heat injury and, in any case, sensitization was not preceded by suppression and was too transient and of insufficient magnitude to account for the observed changes in the pain threshold.

Previous studies of AMHs in monkey and rabbit have found most to be relatively insensitive to heat in normal skin but to become greatly sensitized to heat following a sufficiently intense heating, typically of $53^{\circ} \mathrm{C}$ or higher (Fitzgerald and Lynn, 1977; Campbell et al., 1979). Meyer and Campbell (1981) used a laser thermal stimulator to deliver a radiant heat stimulus of $53^{\circ} \mathrm{C}$ for $30 \mathrm{sec}$ to the glabrous skin of the monkey hand. The responses to heat of $\mathrm{CMH}$ nociceptors within the area of injury were suppressed, while those of AMHs were greatly enhanced." Similarly, in a study of monkey hairy skin, a mild heat injury produced by a $\mathrm{CS}$ of $56^{\circ} \mathrm{C}$ and $7 \mathrm{sec}$ duration (comparable in severity to injuries produced in the present study) sensitized a greater proportion of AMH than CMH nociceptors (Thalhammer and LaMolte, 1982). Thus, both CMH and AMH nociceptors potentially contribute to cutaneous hyperalgesia: a major role is provided by CMHs following mild heat injuries and by AMHs following more severe injuries and/or higher temperatures of injurious heat.

\footnotetext{
${ }^{8}$ A given desired stimulus temperature, when produced by the laser stimulator, would result in a slightly higher skin temperature than that produced by our contact thermal stimulator. This is true since the laser stimulator controls stimulus temperature at a level of about $100 \mu \mathrm{m}$ within the skin (via feedback from a radiometer remote to the skin) (Meyer et al., 1976), whereas the contact stimulator controls temperature just above the skin via feedback from a thermocouple at the skinthermode interface. Thus, a stimulus of $53^{\circ} \mathrm{C}, 30 \mathrm{sec}$, when delivered by the laser, commonly produced a blister (R. A. Meyer, personal communication). The same stimulus delivered by the contact stimulator (or as produced in the study of heat injuries by Moritz and Henriques, 1947) did not blister the skin and was probably 1 to $2^{\circ} \mathrm{C}$ cooler.
}

Only a small proportion of our CMH nociceptors sampled from human nerve exhibited a lowering of the response threshold after the CS. However, as discussed earlier, this sample may not be representative of the whole $\mathrm{CMH}$ population since all of the CMHs had a threshold of $41^{\circ} \mathrm{C}$ prior to the CS. It may be that the endings of these sensitive CMHs were more superficially located in the skin than those of higher threshold nociceptors and that they were stimulated more vigorously and hence were more suppressed following the CS. Other $\mathrm{CMH}$ nociceptors, such as those whose endings lie deeper in the skin or adjacent to the area of injury, would have higher thresholds. These might be less suppressed by the base and test stimuli and therefore exhibit a greater degree of sensitization.

Our analysis of the pain ratings of suprathreshold stimuli and the responses of $\mathrm{CMH}$ nociceptors to these stimuli have revealed the same time course of changes in response magnitude as described in the present paper for threshold measurements. However, the relation that we obtained between magnitude ratings of pain and the magnitude of responses in $\mathrm{CMH}$ nociceptors was neither a simple one (Robinson et al., 1981) nor was it the same for CMHs in monkeys and humans (R. H. LaMotte and J. G. Thalhammer, unpublished observations).

\section{Variables that may influence the changes in pain thresholds and response thresholds of $C M H$ nociceptors following heat injury}

The degree and direction of change in the heat-pain threshold or response thresholds of heat-sensitive nociceptors following injury to the skin will depend upon the type and severity of the injury, the temperatures and sequences of test stimuli delivered, the type of skin stimulated, and the species tested.

Type and severity of injury and the temperatures and sequences of stimuli delivered. The time course of hyperalgesia depends upon the type of injury sustained. Lewis and Hess (1933) noted that hyperalgesia occurred "almost at once" following mechanical or heat injuries but was delayed up to several hours following exposure to UV radiation. Also, the magnitude and the direction of change in the pain threshold depend upon the severity of the injury, that is, on the intensity and duration of the injurious stimulus. Single or multiple presentations of painful heat stimuli each of short duration and relatively low intensity may result in hypoalgesia, i.e., elevated pain thresholds and suppressed pain ratings of suprathreshold stimuli (LaMotte and Campbell, 1978; LaMotte, 1979). At the other extreme, hyperalgesia, or a lowering of the pain threshold, is greatest following stimuli that irreversibly injure the skin. Following application of molten wax, freezing, or UV radiation resulting in a blister and thus damage to the epidermis, the pain threshold was lowered from normal values of, for example, 43 to $45^{\circ} \mathrm{C}$ to 32 to $36^{\circ} \mathrm{C}$ (Lewis and Hess, 1933). Moritz and Henriques (1947) demonstrated that there is an inverse relation between the intensity of a heat stimulus maintained at constant temperature at the surface of the skin and the duration of that stimulus required to produce irreversible injury defined as transepidermal necrosis. Our CS duration of $100 \mathrm{sec}$ is two-thirds of the shortest duration of a $50^{\circ} \mathrm{C}$ stimulus that produces, on at least some occasions, 
irreversible injury to the skin. Although our increase in the duration of a CS of $50^{\circ} \mathrm{C}$ from 60 to $100 \mathrm{sec}$ resulted only in minor, and not significantly greater, decreases in pain thresholds, it still seems probable that the amount of hyperalgesia induced by a reversible heat injury will be greater for longer than for shorter durations of the same temperature of heating. Further, if the stimulus is of insufficient strength, hypoalgesia is likely to occur instead of hyperalgesia.

The degree of change in the response thresholds of nociceptors also may depend upon the severity of the injury but in a more complex way than that for pain thresholds. As shown in the present study, CMH and AMH nociceptors are not sensitized the same amount following a mild heat injury. A heat injury that induced hyperalgesia for several hours lowered the response thresholds of $\mathrm{CMH}$ but not AMH nociceptors. Further, individual nociceptors may differ in their thresholds for the intensities and durations of heat required for their sensitization. For CMHs in the monkey, one or more heat stimuli of at least $45^{\circ} \mathrm{C}$ and of durations typically longer than $20 \mathrm{sec}$ were required to produce decreases in thresholds that varied from 1 to $4^{\circ} \mathrm{C}$ (Beitel and Dubner, 1976b; Croze et al., 1976; Kumazawa and Perl, 1978). As is the case for judgments of pain, the responses of $\mathrm{CMH}$ and AMH nociceptors to nondamaging but painful mechanical or heat stimuli may become suppressed with repetitive stimulations. However, the responses of $\mathrm{CMHs}$ also may be suppressed and not sensitized if heat stimuli are too intense, for example, greater than $55^{\circ} \mathrm{C}$ and 10 sec duration (Kumazawa and Perl, 1978; see also Beitel and Dubner, 1976a, b). Suppression can occur even after sensitization has taken place. Kumazawa and Perl (1978) found that, after the initial sensitization of a $\mathrm{CMH}$, repeated heat stimulations resulted in suppression and then, after a sufficiently long stimulus-free period, sensitization again. The fact that, under certain conditions, suppression can outweigh the sensitizing effects of noxious stimulation might explain why, in one study in humans, rapid, repetitive presentations of heat stimuli blistered the skin without sensitizing a $\mathrm{CMH}$ nociceptor (Gybels et al., 1979), while in another study, a single heat stimulation of $50^{\circ} \mathrm{C}$ and 1 to 2 min duration resulted in suppression and subsequent sensitization of a CMH nociceptor along with parallel changes in the pain thresholds (Torebjörk and Hallin, 1977). Thus, the response thresholds of CMHs, unlike pain thresholds, can be lowered only by stimuli delivered within a window of stimulus-time values. Stimuli of temperatures either beneath or above the window produce a transient suppression of $\mathrm{CMH}$ responses. In contrast, sufficiently intense stimuli above the window may sensitize AMHs dramatically (Campbell et al., 1979; Meyer and Campbell, 1981) and also possibly those CMHs with receptive fields that are adjacent to the most intensely heated area of skin. Possibly, the latter would be less suppressed and more sensitized than those CMHs more vigorously activated.

Types of species and skin stimulated. Nociceptors differ in their susceptibility to the sensilizing effects of an injurious stimulus. The relative proportion of nociceptors of a given type that become sensitized following heat injury may not be the same from one species to the next or for different types of skin within the same species. For example, CMII nociceptors in the rabbit were readily sensitized following a sufficiently intense heat stimulus and the amount of sensitization was directly proportional to the stimulus temperature (Lynn, 1979). In contrast, $\mathrm{CMHs}$ in the rat were considerably less likely to be sensitized by the same stimuli (B. Lynn, personal communication). There are also differences in the degree of sensitization of nociceptors from one region of skin to the next within the same species. In the present study, CMHs in hairy skin were sensitized more (greater decrease in threshold) than $\mathrm{CMHs}$ in the glabrous skin. Also, a greater proportion of AMHs were sensitized, and to a greater degree, in hairy than in glabrous skin. In psychophysical experiments, the same heat injury produced more hyperalgesia and less hypoalgesia for the hairy than the glabrous skin. Further, there were regional differences within glabrous skin, such as less hyperalgesia for the hypothenar than the thenar eminence. We suggest that nociceptive transducers for heat, mechanical, or chemical stimuli externally applied to the skin differ in their responsiveness to sensitivity changes following exposure to chemical substances released by injured tissue. These differences in susceptibility to sensitization may be observed even within the same nociceptor. For example, some AMH or CMH nociceptors, after becoming sensitized to heat, also exhibit sensitization to mechanical stimuli, while others do not (Bessou and Perl, 1969; Thalhammer and LaMotte, 1982). Thus, although CMHs in certain regions of the glabrous skin may have the same sensitivities to heat as those of CMHs in hairy skin, they may be less responsive to the actions of sensitizing chemical substances. Alternatively, there may be less of these substances available to the receptors in glabrous than in hairy skin. The glabrous skin of the hand has an important sensory role during the active manipulation of objects in the environment, while the hairy skin serves primarily a protective function. The predominance of suppression over hyperalgesia in glabrous skin would facilitate the capacity of the hand to function as an organ of sensory discrimination and exploration even in a mildly injurious environment.

\section{Conclusion}

The present study focused on determinations of pain thresholds and response thresholds of nociceptors. We have found that, following a mild heat injury, the time course of changes in the pain thresholds of humans paralleled the time course of changes in the threshold responses of $\mathrm{CMH}$ nociceptors as measured in humans and monkeys. We therefore conclude that altered activity in $\mathrm{CMH}$ nociceptors is a major peripheral neuronal determinant of cutaneous hyperalgesia following a mild heat injury to the skin.

\section{References}

Adriaensen, H., J. Gybels, H. O. Handwerker, and J. Van Hees (1981) Receptive properties of human A-delta fibres. Pain Suppl. 1: 589.

Beck, P. W., H. O. Handwerker, and M. Zimmerman (1974) Nervous outflow from the cat's foot during noxious radiant heat stimulation. Brain Res. 67: 373-386.

Beitel, R. E., and R. Dubner (1976a) Sensitization and depression of C-polymodal nociceptors by noxious heat applied to 
the monkey's face. In Advances in Pain Research and Therapy, J. J. Bonica and D. Albe-Fessard, eds., Vol. 1, pp. 149153, Raven Press, New York.

Beitel, R. E., and R. Dubner (1976b) The response of unmyelinated $(\mathrm{C})$ polymodal nociceptors to thermal stimuli applied to the monkey's face. J. Neurophysiol. 39: 1160-1175.

Bessou, P., and E. R. Perl (1969) Response of cutaneous sensory units with unmyelinated fibers to noxious stimuli. J. Neurophysiol. 32: 1025-1043.

Burgess, P. R., and E. R. Perl (1967) Myelinated afferent fibres responding specifically to noxious stimulation of the skin. J. Physiol. (Lond.) 190: 541-562.

Campbell, J. N., and R. H. LaMotte (1977) Reaction time to first pain in human subjects. Soc. Neurosci. Abstr. 3: 478.

Campbell, J. N., R. A. Meyer, and R. H. LaMotte (1979) Sensitization of myelinated nociceptive afferents that innervate monkey hand. J. Neurophysiol. 42: 1669-1679.

Christensen, B. N., and E. R. Perl (1970) Spinal neurons specifically excited by noxious or thermal stimuli: Marginal zone of the dorsal horn. J. Neurophysiol. 33: 293-307.

Croze, S., R. Duclaux, and D. R. Kenshalo (1976) The thermal sensitivity of the polymodal nociceptors in the monkey. J. Physiol. (Lond.) 263: 539-562.

Darian-Smith, I., K. O. Johnson, and R. Dykes (1973) "Cold" fiber population innervating palmar and digital skin of the monkey: Responses to cooling pulses. J. Neurophysiol. 36: 325-345.

Darian-Smith, I., K. O. Johnson, C. LaMotte, Y. Shigenaga, P. Kenins, and P. Champness (1979) Warm fibers innervating palmar and digital skin of the monkey: Responses to thermal stimuli. J. Neurophysiol. 42: 1297-1315.

Dodt, E., and Y. Zotterman (1952) The discharge of specific cold fibres at high temperatures (the paradoxical cold). Acta Physiol. Scand. 26: 358-365.

Dubner, R., R. Sumino, and W. I. Wood (1975) A peripheral "cold"fiber population responsive to innocuous and noxious thermal stimuli applied to the monkey's face. J. Neurophysiol. 38: 1373-1389.

Dubner, R., D. D. Price, R. E. Beitel, and J. W. Hu (1977) Peripheral neural correlates of behavior in monkey and human related to sensory-discriminative aspects of pain. In Pain in the Trigeminal Region, D. J. Anderson and B. Matthews, eds., pp. 57-66, Elsevier, Amsterdam.

Fitzgerald, M., and B. Lynn (1977) The sensitization of high threshold mechanoreceptors with myelinated axons by repeated heating. J. Physiol. (Lond.) 265: 549-563.

Georgopoulos, A. P. (1976) Functional properties of primary afferent units probably related to pain mechanisms in primate glabrous skin. J. Neurophysiol. 39: 71-83.

Gybels, J., H. O. Handwerker, and J. Van Hees (1979) A comparison between the discharges of human nociceptive nerve fibres and the subject's ratings of his sensations. J. Physiol. (Lond.) 292: 193-206.

Hallin, R. G., and H. E. Torebjörk (1976) Studies on cutaneous $A$ and $C$ fibre afferents, skin nerve blocks and perception. In Sensory Functions of the Skin in Primates, Y. Zotterman, ed., pp. 137-148, Pergamon Press, Oxford.

Hardy, J. D., H. G. Wolff, and H. Goodell (1952) Pain Sensations and Reactions, Williams and Wilkins, Baltimore.

Harris, R. J. (1975) A Primer of Multivariate Statistics, Academic Press, New York.

Hensel, H., and K. K. A. Boman (1960) Afferent impulses in cutaneous sensory nerves in human subjects. J. Neurophysiol. 23: $564-578$.

Hensel, H., and A. Iggo (1971) Analysis of cutaneous warm and cold fibers in primates. Pfluegers Arch. 329: 1-8.

Iggo, A. (1959) Cutaneous heat and cold receptors with slowly conducting (C) afferent fibres. Q. J. Exp. Physiol. 44: 362370.
Iggo, A. (1960) Cutaneous mechanoreceptors with afferent C fibres. J. Physiol. (Lond.) 152: 337-353.

Iggo, A. (1969) Cutaneous thermoreceptors in primates and subprimates. J. Physiol. (Lond.) 200: 403-430.

Iriuchijima, J., and Y. Zotterman (1960) The specificity of afferent cutaneous C-fibres in mammals. Acta Physiol. Scand. 49: 267-278.

Kenshalo, D. R., and R. Duclaux (1977) Response characteristics of cutaneous cold receptors in the monkey. J. Neurophysiol. 40: 319-332.

Kenshalo, D. R., Jr., R. B. Leonard, J. M. Chung, and W. D. Willis (1979) Responses of primate spinothalamic neurons to graded and to repeated noxious heat stimuli. J. Neurophysiol. 42: $1370-1389$.

Kenshalo, D. R., Jr., G. J. Giesler, R. B. Leonard, and W. D. Willis (1980) Responses of neurons in primate ventral posterior lateral nucleus to noxious stimuli. J. Neurophysiol. 43: 1594-1614.

Konietzny, F., and H. Hensel (1975) Warm fiber activity in human skin nerves. Pfluegers Arch. 359: 265-267.

Kumazawa, T., and E. R. Perl (1977) Primate cutaneous sensory units with unmyelinated (C) afferent fibers. J. Neurophysiol. 40: $1325-1338$.

Kumazawa, T., and E. R. Perl (1978) Excitation of marginal and substantia gelatinosa neurons in the primate spinal cord: Indications of their place in dorsal horn functional organization. J. Comp. Neurol. 177: 417-434.

LaMotte, R. H. (1979) Intensive and temporal determinants of thermal pain. In Sensory Functions of the Skin in Primates, D. Kenshalo, ed., pp. 327-358, Pergamon Press, Oxford.

LaMotte, R. H., and J. N. Campbell (1978) Comparison of the responses of warm and nociceptive C-fiber afferents in monkey with human judgments of thermal pain. J. Neurophysiol. 41: 509-528.

Lewis, T., and W. Hess (1933) Pain derived from the skin and the mechanism of its production. Clin. Sci. 1: 39-61.

Long R. R. (1977) Sensitivity of cutaneous cold fibers to noxious heat: Paradoxical cold discharge. J. Neurophysiol. 40: 489502.

Lynn, B. (1977) Cutaneous hyperalgesia. Br. Med. Bull. 33: 103-108.

Lynn, B. (1979) The heat sensitization of polymodal nociceptors in the rabbit and its independence of the local blood flow. J. Physiol. (Lond.) 287: 493-507.

Lynn, B. (1980) Heat pain sensitivity of human skin after mild heat injury and its lack of dependence on the local blood flow. Pain 8: 189-196.

Lynn, B., and E. R. Perl (1977) A comparison of four tests for assessing the pain sensitivity of different subjects and test areas. Pain 3: 353-365.

MacKenzie, R. A., D. Burke, N. F. Skuse, and A. K. Lethlean (1975) Fibre function and perception during cutaneous nerve block. J. Neurol. Neurosurg. Psychiatry 38: 865-873.

Meyer, R. A., and J. N. Campbell (1981) Myelinated nociceptive afferents account for the hyperalgesia that follows a burn to the hand. Science 213: 1527-1529.

Meyer, R. A., R. E. Walker, and V. B. Mountcastle (1976) A laser simulator for the study of cutaneous thermal and pain sensations. IEEE Trans. Biomed. Eng. 23: 54-60.

Moritz, A. R., and F. C. Henriques, Jr. (1947) Studies of thermal injury. II. The relative importance of time and surface temperature in the causation of cutaneous burns. Am. J. Pathol. 23: 695-720.

Perl, E. R. (1968) Myelinated afferent fibres innervating the primate skin and their response to noxious stimuli. J. Physiol. (Lond.) 197: 593-615.

Perl, E. R., T. Kumazawa, B. Lynn, and P. Kenins (1976) Sensitization of high-threshold receptors with unmyelinated (C) afferent fibers. Prog. Brain Res. 43: 263-276. 
Price, D. D., R. Dubner, and J. W. Hu (1976) Trigeminothalamic neurons in nucleus caudalis responsive to tactile, thermal, and nociceptive stimulation of monkey's face. J. Neurophysiol. 39: 936-953.

Price, D. D., J. W. Hu, R. Dubner, and R. H. Gracely (1977) Peripheral suppression of first pain and central summation of second pain evoked by noxious heat pulses. Pain 3: 57-68.

Price, D. D., R. L. Hayes, M. Ruda, and R. Dubner (1978) Spatial and temporal transformations of input to spinothalamic tract neurons and their relation to somatic sensations. J. Neurophysiol. 41: 933-947.

Robinson, C. J., R. H. LaMotte, J. G. Thalhammer, and H. E. Torebjörk (1980) Detection threshold as an objective indicator of sensitivity to thermal pain in normal and hyperalgesic skin in humans. Soc. Neurosci. Abstr. 6: 246.

Robinson, C. J., H. E. Torebjörk, and R. H. LaMotte (1981) Simultaneous recordings from humans of pain sensations and nociceptor activity before and after cutaneous hyperalgesia. Soc. Neurosci. Alustr. 7: 340.

Sumino, R., R. Dubner, and S. Starkman (1973) Responses of small myelinated 'warm' fibers to noxious heat stimuli applied to the monkey's face. Brain Res. 62: 260-263.

Thalhammer, J. G., and R. H. LaMotte (1982) Spatial proper- ties of nociceptor sensitization following heat injury of the skin. Brain Res., 231: 257-265.

Torebjörk, H. E., and R. G. Hallin (1973) Perceptual changes accompanying controlled preferential blocking of $\mathrm{A}$ and $\mathrm{C}$ fibre responses in intact human skin nerves. Exp. Brain Res. 16: $321-332$.

Torebjörk, H. E., and R. G. Hallin (1974) Identification of afferent $\mathrm{C}$ units in intact human skin nerves. Brain Res. 67: 387-403.

Torebjörk, H. E., and R. G. Hallin (1977) Sensitization of polymodal nociceptors with $\mathrm{C}$ fibres in man. Proc. Int. Union Physiol. Sci. 13: 758.

Van Hees, J., and J. Gybels (1972) Pain related to single afferent C-fibers from human skin. Brain Res. 48: 397-400.

Van Hees, J., and J. Gybels (1981) C nociceptor activity in human nerve during painful and non-painful skin stimulation. J. Neurol. Neurosurg. Psychiatry 44: 600-607.

Zotterman, Y. (1936) Specific action potentials in the lingual nerve of cat. Scand. Arch. Physiol. 75: 105-120.

Zotterman, Y. (1939) Touch, pain and tickling: An electrophysiological investigation on cutaneous sensory nerve. J. Physiol. (Lond.) 95: 1-28. 